\title{
Review \\ Community-Based Microgrids: Literature Review and Pathways to Decarbonise the Local Electricity Network
}

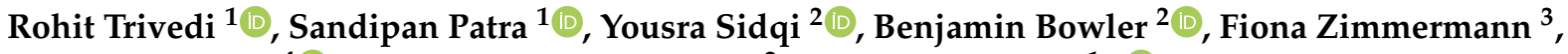 \\ Geert Deconinck ${ }^{4}$ (D), Antonios Papaemmanouil ${ }^{2}$ and Shafi Khadem ${ }^{1, *(\mathbb{D})}$ \\ 1 International Energy Research Centre, Tyndall National Institute, T12 R5CP Cork, Ireland; \\ rohit.trivedi@ierc.ie (R.T.); sandipan.patra@ierc.ie (S.P.) \\ 2 Competence Center for Digital Energy and Electric Power, Lucerne University of Applied Sciences and Arts, \\ 6048 Horw, Switzerland; yousra.sidqi@hslu.ch (Y.S.); benjamin.bowler@hslu.ch (B.B.); \\ antonios.papaemmanouil@hslu.ch (A.P.) \\ 3 Institute of Sustainable Energy, HES SO, Applied Science University of Western Switzerland, \\ 1950 Sion, Switzerland; fiona.zimmermann@hevs.ch \\ 4 KU Leuven_ESAT_ELECTA/EnergyVille, 3001 Leuven, Belgium; geert.deconinck@kuleuven.be \\ * Correspondence: shafi.khadem@ierc.ie
}

check for

updates

Citation: Trivedi, R.; Patra, S.; Sidqi,

Y.; Bowler, B.; Zimmermann, F.;

Deconinck, G.; Papaemmanouil, A.; Khadem, S. Community-Based

Microgrids: Literature Review and

Pathways to Decarbonise the Local Electricity Network. Energies 2022, 15 918. https://doi.org/10.3390/ en15030918

Academic Editor: Abu-Siada Ahmed

Received: 22 December 2021

Accepted: 21 January 2022

Published: 27 January 2022

Publisher's Note: MDPI stays neutral with regard to jurisdictional claims in published maps and institutional affiliations.

Copyright: (C) 2022 by the authors. Licensee MDPI, Basel, Switzerland. This article is an open access article distributed under the terms and conditions of the Creative Commons Attribution (CC BY) license (https:// creativecommons.org/licenses/by/ $4.0 /)$

\begin{abstract}
This article addresses the suitable approaches for empowering energy citizens and smart energy communities through the development of community-based microgrid (C-MG) solutions while taking into consideration the functional architectural layers and system integration topologies, interoperability issues, strategies for consumer-centric energy trading under the local electricity market (LEM) mechanism, and socio-economic aspects. Thus, this article presents state-of-the-art microgrid solutions for the smart energy community along with their motivation, advantages and challenges, comprehensibly contrasted between the recommended generic architecture and every other reported structure. The notion of LEM for peer-to-peer (P2P) energy exchange inside a transactive energy system based on a flexible consumer-centric and bottom-up perspective towards the participation in the wholesale electricity market (WEM) is also reviewed and critically explored. Furthermore, the article reviews the interoperability issues in relation to the development of C-MG including energy trading facilities. The article's overall contribution is that it paves the path for advanced research and industrialisation in the field of smart energy communities through the analytical recommendations of the C-MG architecture and DER (distributed energy resource) integration structure, considering the future trend of local energy markets and socio-economic aspects.
\end{abstract}

Keywords: microgrid; community microgrid; energy communities; microgrid architecture; interoperability; local energy market; hybrid AC-DC distribution; microgrid social aspects; peer-topeer energy trading

\section{Introduction}

To promote the carbon-neutral community, the European Union (EU) is committed to placing the consumer at the centre of the energy transition. EU initiatives encourage energy-active citizens and a consumer-centric energy transition. Hence, many national and EU projects are ongoing that focus on consumer-centric local energy systems, networks, and communities. For example, through the collaborative R\&D calls, the EU supports projects on the development of solutions and tools for the optimisation of the local energy network (LEN) [1,2]. Under this theme (LEN), the ongoing and future proposed projects also consider the concept of local energy communities, renewable energy communities and citizen energy communities. These terminologies are also defined in EU directives [3].

The shift towards a consumer-centric energy transition has placed particular emphasis on decarbonising the low-voltage distribution networks. The concept of the microgrid is one of the advancements in the electricity distribution network that supports such 
decarbonisation using distributed energy resources (DERs) that are independent of or only partially dependent on the main grid. It has also empowered consumers to support the grid by activating their assets for energy services whenever required. Consumers can also support each other by forming a microgrid that can be managed or operated by the users of a community with or without the support from an operational entity, thereby creating a community-based microgrid (C-MG).

The microgrid concept is well established and has been the subject of significant research efforts in recent years. With the advancement of technologies, consumers' interest in participating in energy trading/sharing with neighbours, the local or wholesale energy market, and community-based microgrid solutions are thus getting more important. However, open questions remain regarding microgrid system integration, structure, energy sharing and trading mechanisms, technical performance of micro-grids in relation to the local distribution system constraints, micro-grid management and operation, cost efficiency, and socio-economic factors relating to consumer empowerment and engagement. From the microgrid system structure point of view, DERs can be placed anywhere in the microgrid networks either near to the central controller or dispersed to the consumers' end, as shown in Figure 1. From the active consumers' participation point of view, we are considering the C-MG solutions, where DERs are mostly placed behind the meter at the consumers' end, as shown in Figure 1b.

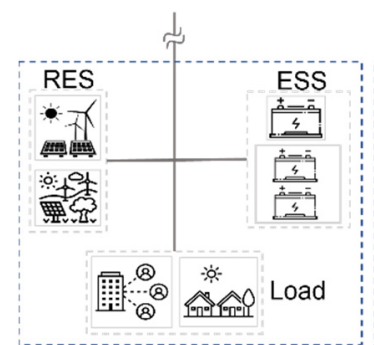

(a)

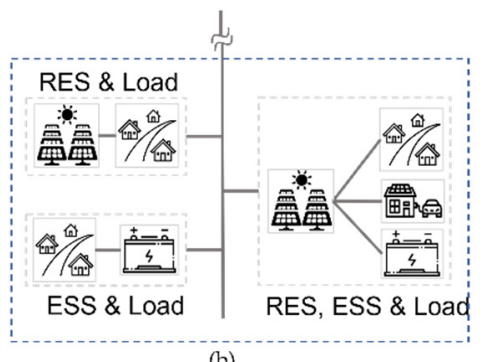

(b)

Figure 1. General structure of microgrids/community-based microgrids: (a) DERs (RES, ESS) are in centralised mode; (b) DERs are in distributed mode and close to the consumers' end and mostly behind the meter.

From a system integration point of view, the energy network solution for communities can be non-place based (i.e., specific geographic location) or place based (i.e., within a geographic location) [4]. As the solutions are consumer-centric and consumers' active participation in the energy management/energy market is important, the local energy system for communities is in general considered to be the local energy network, mainly the local electricity distribution network. Local energy/electricity network solutions are variously termed microgrids, local area energy networks [5], community-based microgrids [6,7], community grids [8], logical energy networks [9], smart local networks [10], etc., with all being represented in some form of microgrid structure.

One of the key socio-economic objectives for moving towards community-based microgrids is to ensure affordable electricity to all users and the provision of low cost/noneconomic electricity to vulnerable customers [11]. In addition, the common objective of these networks is to empower consumers. The Council of European Energy Regulators (CEER) [12] also presents the strategy of empowering consumers for energy transition by:

- $\quad$ DER integration and innovative incentivisation;

- Making consumers active to deliver to and get support from the flexible energy system;

- New consumer-centric market and business models.

This energy transition will be successful if consumers are well informed and supported throughout this transformation, which will increase the responsibility and accountability of governments, utilities and relevant stakeholders [13]. Consumer-focused smart integration of renewable resources leads to increased active consumer participation that consequently brings added advantages such as a better choice of supply, the possibility to produce and 
sell electricity and access to energy markets, making the overall system more transparent. In this regard, community-based microgrids have gained popularity in recent years. The benefits of allowing community microgrids, such as cheaper energy prices for the community, decarbonisations, and enhanced ancillary services to the utility grid, have been highlighted in [14] and in [15]. As the community microgrid brings together critical loads and dispersed energy resources from various owners, the authors of the articles [16,17], introduce substantial new operational and commercial concepts. Using a community microgrid distribution system, this paper aims to address essential features, operational issues, and viable solution techniques for future community microgrid distribution networks.

One of the key elements to developing DER rich C-MG is the structure or topology in which the assets and users in the community can be well integrated and connected. Given the heterogeneity of households (care homes, students, family, tenants) with different electricity consumption profiles, the real-time management of local generation and consumption must be maintained at all times and the network should be able to carry the power flow satisfactorily without violating the system's constraints [18]. There remain significant challenges in developing the community network in such a way that it can accommodate all the community-owned resources and control the whole system reliably. The common technical challenges include voltage level and generation variability, harmonic distortion, resonance, stability, low inertia system stability, islanding detection, network protection, etc. A review of these technical issues and possible solutions concerning community-based grid/microgrids is presented in [8].

Community-based microgrids must be operated and managed in an adaptable and flexible manner considering the common interests of all the key stakeholders [19]. Some of the key energy trading challenges are balancing local generation and demand, prosumer participation and interaction, secure transactions, resilient communication infrastructure, and prosumer welfare [20]. In addition, apart from the technical benefits derived at the local level, it is crucial to ensure the cost efficiency of the local energy system. Since the community users will not be fully utilising the whole transmission and distribution network, but rather a part of the low-voltage network, the network utilisation tariff must be considered and benefits such as reduced grid fee should be directed to the community [18]. In light of the increased penetration of solar and battery energy storage systems, a microenergy market is suggested in [21] for smart household energy trading in low-voltage distribution systems. Additionally, a microbalance market is also proposed by the authors to alleviate congestion caused by unanticipated energy imbalances. The topology of the C-MG will play an important role in deciding the network tariff based on the complexity and management of the whole system. Furthermore, focus should also be given to the alleviation of energy poverty amongst the non-members of the community, especially individuals who cannot afford to make investments in renewables [19]. The community can support all the consumers of this group by equally dividing their net profit and avoiding social discrepancy.

Exploration to find the solution to the challenges gives rise to evolving the architectures of community microgrids in a way that the facilitation of DERs becomes easier and prosumers can benefit from the best network design topology. In this respect, the C-MG structure development has focused on the following, showing that the architecture should consider DER integration/control and market operations simultaneously:

- Ancillary services to the grid/inter-community microgrids;

- Multi-scale storage management (small, medium, large scale storage);

- Computational complexity on network trading and simulations;

- Maximum power injection limit on inverters;

- Regulation and grid code compliance on max capacity installation (prosumer with large storage installed capacity can earn more revenue);

- Network tariff based on the utilisation of part of the network;

- Avoiding conflicts among stakeholders (DSO, Retailer) based on personal interests; 
- Real-time coordination from the top level (DSO, C-MG operator) to the bottom level (prosumer assets);

The state of the art of the C-MG design is geared at resolving local community-based peer-to-peer (P2P) energy trade challenges, with the complexity and requirements of the community varying from one another. The purpose of this article is to offer a thorough review of the evolution of C-MG. In this respect, the key contributions of the article are:

- A systematic evaluation of the existing literature and construction of a generalised framework for C-MG.

- All feasible C-MG structure/topology on the basis of DER and grid integration are summarised and evaluated.

- The investigation of interoperability in the context of the development of a C-MG.

- In contrast, this review also provides a comprehensive understanding of the consumercentric local electricity market that would be suitable for C-MG structures.

- The opportunities and constraints of socioeconomic elements in the context of creating C-MG are also explored.

In summary, this study presents a comprehensive analytical assessment as well as recommendations for the development of C-MGs.

The rest of the article is organised as follows considering the above-mentioned contributions. The formation of the research questions to be addressed in this review article is provided in the methodology, Section 2. The architectural evaluation of the C-MG is reviewed and described in Section 3, and a generalised C-MG structure is proposed. Section 4 addresses the opportunities and problems associated with DERs and grid integration in the context of C-MG topological evaluation. Section 5 highlights the relevant interoperability issues. Section 6 discusses the limitations and opportunities associated with the consumers' participation in LEM and WEM through the C-MG solutions. Section 7 briefly reviews the evolution of C-MG in light of its societal implications and the importance of a Living Lab. Section 8 presents a summary of the findings and recommendations, which is followed by the conclusion in Section 9.

\section{Methodology}

The fundamental 3-dimensional smart grid architecture model (SGAM) [22] envelopes all the possible entities and operations in a smart grid network. Taking it as a reference, this paper extensively reviews the reported architectures for different possible C-MG topologies and provides recommendations for the following research questions:

- Architectural framework: Smart grid and microgrid networks should have a common architectural framework. When the microgrid structures/topologies are more concerned with closer integration at the community level to engage and empower consumers, the social aspect is an important issue there. Does the existing framework then consider this issue?

- $\quad$ C-MG Structure: Different types of structures exist in the research, development and demonstration space. All the existing solutions have some pros and cons when it comes to the benefit of consumers as well as the network operators. From the energyactive consumer point of view (including consumers with demand response facilities, prosumers), what type of microgrid structures could be most beneficial for their active participation in the energy transition?

- Interoperability: When it comes to microgrids/C-MG solutions, researchers are rarely focused on interoperability issues. In most cases, the importance of interoperability is also not clear. In cases of C-MGs, how can communication among the DERs, active consumers, and operators within the microgrids, as well as their interactions with the smart grid for ancillary services/flexibility, be achieved?

- Market integration: Local Electricity Market (LEM) concepts are developing and getting more important in energy communities. However, LEM impacts on the distribution network are not well researched. Considering the same impact in the microgrid 
networks, what type of C-MG structures could be more suitable for active consumers to participate in local electricity trading/sharing? In relation to consumer engagement, how they can participate in the wholesale electricity market (WEM) as well?

- Social aspect: It is well accepted that microgrids have lots of technical, economical, and environmental benefits. The integration of microgrids in energy communities to empower energy citizens and identify the social benefits is not well researched yet. The literature on microgrids needs to be assessed to identify the social research methods associated with the development process of C-MGs. What type of C-MG structure could be beneficial for the community users to increase their social bonding? How could a Living Lab methodology benefit society in managing and operating the local energy community-based microgrids?

Each section below provides a brief review of the existing literature on the relevant topic and proposes some solutions in response to the research questions.

\section{C-MG Architecture}

In this section, the SGAM model is used as a baseline architecture to understand the microgrid operational framework. The existing architectures are comprehensively reviewed and the recommendation for the C-MG operational layers are presented.

\subsection{Reported Architecture}

The design and development of C-MG architecture is an important aspect to consider before addressing the underlying enabling technologies and their performance in relation to the objectives of the C-MG. In the renewable energy era, it becomes challenging to identify a flexible and sustainable architecture that focuses on resource specification and allocation to properly utilise the energy in a community-based microgrid environment. The SGAM model [21] represents five interoperable layers, namely, component, communication, information, function and business layer features, by domains and the zones of the operations. Focusing more on market participation, a multi-layered architecture for the P2P deregulated energy market is discussed in [23], with five layers describing the management and operations of the system. The device layer contains physical components installed at individual premises, factories and assets in the electrical distribution network. The smart meter layer is framed as a single entity that includes collective information of all the devices given the users have no authority/ownership in this layer. Assets such as smart meters are totally owned by the DSO/aggregator or any responsible third party to minimise the risk of self-beneficial manipulation. The third layer, the transmission layer, facilitates a communication channel between smart meters and DSO or aggregator. The communication layer features end-user integration in the P2P energy market. Different technologies, such as the smart contract, blockchain, etc., that can provide users to interact with other users or entities to sell/buy the energy fall into this category. The topmost layer, the management layer, is responsible for decision-driven data management, market regulation, technical aspects of a network such as generation and load demand balance, power quality management and grid stability.

Authors in [24] have presented a functionality-based architecture focusing on microgrids, nanogrids and picogrids. The first layer presented is the physical layer that involves all the physical components including DERs, ESS, power electronics equipment and other physical loads. The second layer is the communication layer, which focuses on the robust infrastructure for the reliable sharing of data and information among different layers to carry out the desired functions in each layer. The third layer is described as the intelligence layer, which involves all the control actions to make the best decisions for the given circumstances in the microgrid environment. The fourth layer is the business model layer, which includes the business model options for different entities involved in a specific type of services and management in the microgrid networks. The final layer concludes with the regulation and policies needed to maintain the integrity of all the entities involved in the different levels of microgrids. 
A five-layer technology framework for microgrids is also suggested in [25]. Layer 0 includes physical assets owned by users and network operators. Layer 1 consists of protection and control of the individual equipment and the entire system. Layer 2 deals with the automation of the process involved in microgrid operation and control and further coordinates with layer 1 . Layer 3 comprises resource optimisation, scheduling and dispatching considering cost minimisation as the objective function. The last layer includes the interface with the energy market for the various grid services, including outage management. It is to be noted that the communication channel is not included in the layers.

In contrast to the architectures already described, in [26] different layers have been differentiated and categorised as internal and external layers. The internal layer includes infrastructure, communication, and operation and control in microgrids, while the external layer consists of policies and standards, business and climate conditions. All the layers are in in accordance with those featured in other reviewed literature, except the climate conditions layer, which includes the climatic effect. It is described that the location is one of the important factors, as it is weather dependent and can affect microgrid planning.

Further, a three-layer-based transactive energy management system is proposed in [27], for the community microgrid, where the lower layer is the user layer with a home energy management system, smart meter and Message Queuing Telemetry Transport (MQTT). The second layer is the communication system's backbone, and it ultimately assists in communicating with the top layer, which is referred to as the 'aggregator'. A transactive energy management system is used by the top layer 'aggregator' to manage the wholesale market and auxiliary services.

Table 1 depicts the various C-MG architectural levels, together with existing and proposed work. For moving towards a better energy transition, smart grid network development, and communication among the networks, we understand that the practised microgrid architecture must be aligned with the smart grid architecture. Hence, the proposed architecture is the most generalised and optimised design for the C-MG, taking into account all factors, such as energy-efficient and stable network (voltage, frequency, and $\mathrm{PQ}$ regulation, power management), communication requirements for developing demand response/intelligent energy trading, aggregator business requirements, and so on.

Table 1. Comparison of existing and proposed C-MG architecture.

\begin{tabular}{|c|c|c|c|c|c|c|}
\hline SGAM & \multicolumn{6}{|c|}{ Microgrid Architecture } \\
\hline [22] & [20] & [23] & [24] & [25] & [26] & This Work \\
\hline $\begin{array}{l}\text { Component } \\
\text { layer }\end{array}$ & $\begin{array}{c}\text { Power Grid } \\
\text { layer }\end{array}$ & Device layer & $\begin{array}{c}\text { Infrastructure } \\
\text { layer }\end{array}$ & $\begin{array}{l}\text { Physical } \\
\text { equipment }\end{array}$ & Infrastructure & Physical layer \\
\hline Comm. layer & & $\begin{array}{c}\text { Smart meter } \\
\text { layer }\end{array}$ & Comm. Layer & $\begin{array}{l}\text { Protection and } \\
\text { control }\end{array}$ & Communications & ICT layer \\
\hline $\begin{array}{l}\text { Information } \\
\text { layer }\end{array}$ & ICT layer & $\begin{array}{c}\text { Transmission } \\
\text { layer }\end{array}$ & \multirow{2}{*}{$\begin{array}{l}\text { Intelligence } \\
\text { layer }\end{array}$} & $\begin{array}{l}\text { Automation } \\
\text { and control }\end{array}$ & $\begin{array}{l}\text { Operation and } \\
\text { control }\end{array}$ & Control layer \\
\hline Function layer & Control layer & $\begin{array}{l}\text { Communication } \\
\text { layer }\end{array}$ & & $\begin{array}{l}\text { Optimisation } \\
\text { and dispatch }\end{array}$ & $\begin{array}{l}\text { Climate } \\
\text { conditions }\end{array}$ & \multirow{2}{*}{$\begin{array}{c}\text { Market and } \\
\text { business }\end{array}$} \\
\hline Business layer & Business layer & $\begin{array}{c}\text { Management } \\
\text { layer }\end{array}$ & $\begin{array}{l}\text { Business } \\
\text { models }\end{array}$ & $\begin{array}{c}\text { Market } \\
\text { operations }\end{array}$ & Business & \\
\hline & & & $\begin{array}{l}\text { Regulatory } \\
\text { framework }\end{array}$ & & $\begin{array}{l}\text { Policies and } \\
\text { standards }\end{array}$ & $\begin{array}{l}\text { Regulatory } \\
\text { layer }\end{array}$ \\
\hline
\end{tabular}

\subsection{Proposed Architecture for Designing C-MG}

All the reported architectures are more focused on solving local community-based P2P energy trading issues, depending on the complexity and the requirement of the community. Some of these lightly cover the grid integration, enabling technology, functional aspects and business models issues. This article proposes a three-dimensional generalised architecture for a microgrid environment, most importantly C-MGs focusing on easy integration and 
communication with the other smart grid networks. It also emphasises user engagement and participation in the different energy markets. Thus, this structure aligns with the smart grid SGAM layers, along with focusing on the interoperable layer and social aspects in the architectural framework. The suggested architecture is comprised of five levels, as shown in Figure 2. The proposed architecture considers "social aspects" as an important part of forming C-MG for energy-active consumers. In the part that follows, all of the suggested layers are justified and described.

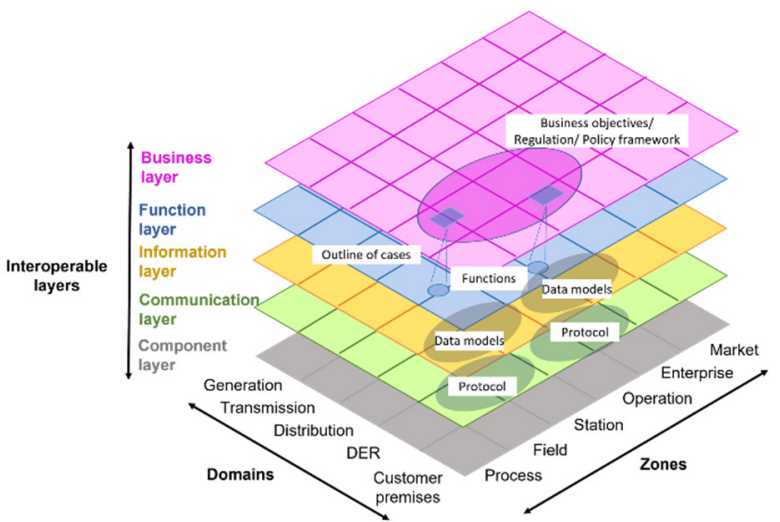

(a)

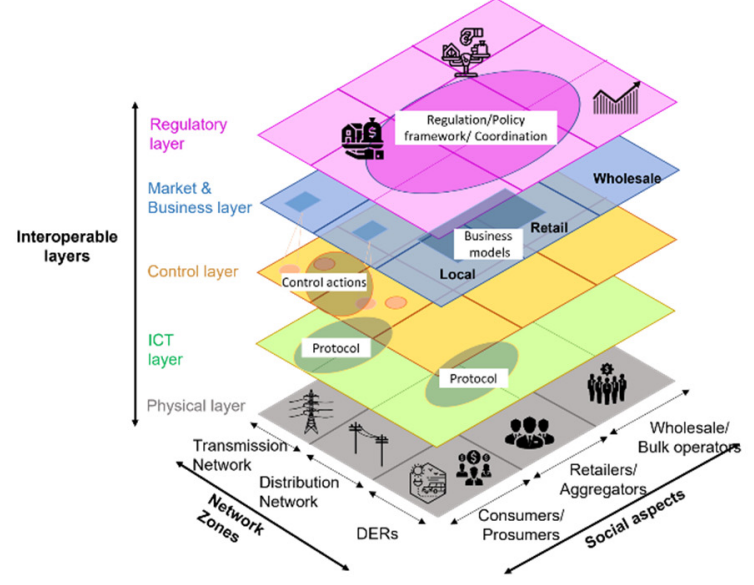

(b)

Figure 2. (a) SGAM architecture; (b) community-based microgrid architecture.

\subsubsection{Physical Layer}

This layer considers all the physical components in the electrical distribution network and energy communities. Each prosumer (or group of prosumers) has an energy management system (EMS) that can manage devices, typically comprising DERs, smart loads, and smart meters. There can be a set of different structures in which the physical elements are connected in the microgrid network. Microgrid structures are discussed in detail in Section 4 . The physical layer is data enriched and is the layer from which most data will come. Typical data include consumption and local generation profiles, forecasting data, device usage and asset life span details. The quality, resolution and granularity of the data play an important role in the entire microgrid functionality and operation. The data logging in the EMS from individual household/production assets can be organised separately or collectively aggregated at a higher level such as buildings, community users, or companies. The data should enable decisions and actions and provide benefits to the end-users. To bring more benefits to the users, their active market participation should be considered. As shown in Figure 2, there can be three different market segments where users can interact, namely, local, retail and wholesale energy markets. For this to happen, the required data must be properly shared through the communication channel.

\subsubsection{ICT Layer}

The information and communication layer has a pivotal role to play in the whole architecture. The data can be transmitted through different communication protocols, such as Message Queuing Telemetry Transport (MQTT), Data Distribution Service (DDS), Power-Line Communication (PLC), Wi-Fi, Long-Range Wide-Area Network (LoRaWAN), etc., depending upon the appropriateness and distance of communication. The selection of protocols can affect numerous aspects, such as scalability, regulatory compliance and energetic footprint [23]. Issues such as connection drops and finite bandwidth will lead to low-quality data, which will subsequently impact the control decisions, meaning that the entire operation can malfunction. Information security will be another major area that should be adopted to ensure data privacy, reliability and trustworthiness. Ranging from 
control, market trading to high-level regulation and management, information sharing and proper communication are key to having a reliable operation of the whole system.

\subsubsection{Control Layer}

The control layer includes critical functionality to operate and maintain the reliable operation of the microgrid. To integrate the DERs and associate them to the energy market, ensuring fail-safe operation of the system, the control layer has a key role to play. This layer interacts with the EMS installed in the physical layer through the communication channel. The control operation can be centralised, decentralised and distributed depending upon the adoption strategy. In general, it facilitates the following control operations:

- Real-time balancing energy consumption and demand in the community microgrids

- Network performance control (power quality, power flow, outage etc.)

- Resource identification and allocation for appropriate action

- $\quad$ Provision of decisions for effective market participation

The control layer will interact with other layers to collect information such as prosumer level energy consumption/generation profile, electrical network constraints, energy storage charging/discharging rate and most updated state of charge (SoC), the status of smart loads for demand response, etc. The controllers will then perform and take action based upon the defined controlling algorithm. The control layer also generates critical information to enable users to take part in the energy market. Accurate prediction/forecasting is also an important part of the control mechanism. Nowadays, artificial intelligence/machine learning approaches are becoming more important in this space [28].

\subsubsection{Market and Business Layer}

The whole set of market operations and business should be facilitated by this layer. The assets in the physical layer can be made accessible to the energy market. Different appropriate market structures can be evolved in this layer and users can directly interact to sell their excess energy either for other users or for grid support services. Tariff/price setting, energy delivery and order settlement will all fall into this layer. The participation of users in this layer is only possible if they have their assets ready to dispatch/control as per the requirement or interests. Discussion on different business models has been done in [29], considering the regularised and liberalised structures of the existing markets. Business models can be developed based on two broad perspectives: first, an internal market focusing on the relationship between asset owners and the key stakeholders; second, the model that focuses on policies, markets and ancillary services.

Researchers in [30] have identified the market gaps that originated mostly due to the direct financial interests between DER owners and the end consumers. As identified in [31], the value of DER units can be capitalised by introducing the local market between consumers and owners. Enabling local trading will benefit the countries/regions that lack robust financial incentives. However, this could introduce issues such as lowering the profits made by DSO and local energy suppliers, since this is like a user-to-user deal and the supplier will have no involvement in this transaction; moreover, DSO will encounter reduced use of system charges. To successfully engage the local trading, a common platform with an efficient market clearing mechanism must be developed that shares the necessary information, and the benefits from LEM can also be transferred to DSO and energy suppliers. This business model will create a fair deal for existing players and provide an opportunity for new players to step in. Another issue identified in [30] stresses financial incentives and their contribution to values derived from LEM transactions. For example, DERs with highly time-invariant support schemes such as Feed-in-Tariff (FiT) will try to deliver more energy to their maximum capacity, which will be unfair and can discriminate among DERs with no financial support [32]. 


\subsubsection{Regulation Layer}

Being the top-level layer, the regulation layer has all the necessary information needed to make informed decisions and regulate the operation of the system. It will involve a legal framework, protocol standards, consumer rights and welfare, and monitoring the process, followed by utilities and other stakeholders. It will also ensure the role of different entities and their coordination in various layers to have clear distinctive functions to be offered by each entity. In brief, the key functionalities and the interaction among the five layers of the proposed C-MG architecture are presented in Figure 3.

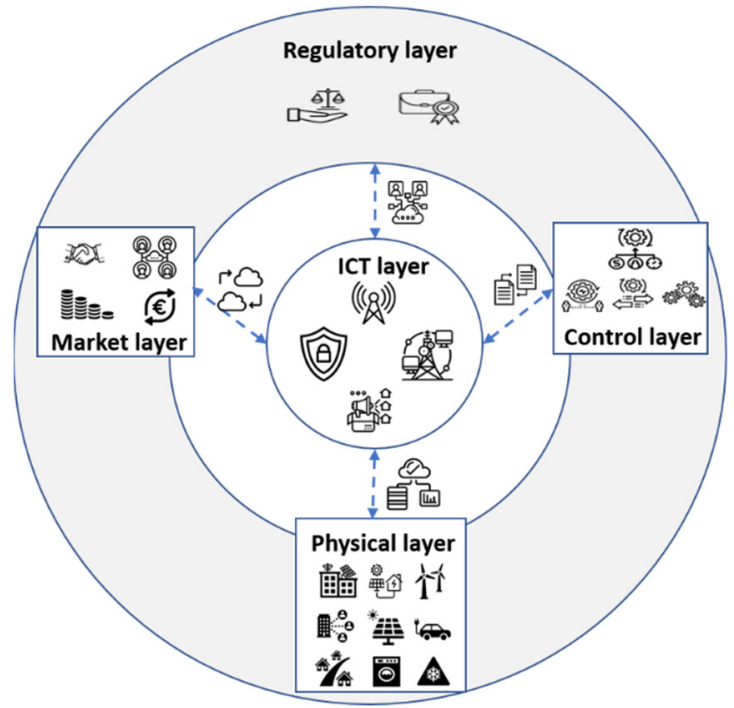

Figure 3. Key functions and interaction among different architectural layers.

The suggested generalised approach, comprised of five levels, are discussed extensively. The effective operational and most data-enriched physical layer of the C-MG has to be reviewed further in order to understand the operational topology for an efficient MG structure. In the following section, C-MG structures are reviewed based on the DERs, load and grid connection.

\section{C-MG Topology/Structure}

An optimal balance between the high uptake of DERs at various geographical areas and load demand nodes in a constrained region must be achieved via the use of efficient microgrid architecture, which will aid in the enhancement of community participation in the electricity system [33]. The authors in the article [34] discuss the role of various renewable energy sources (RES), the evolution of energy storage technologies, and the centralised and decentralised strategies used to coordinate the accompanying energy management. The smart network infrastructure will appropriately connect and manage the randomly installed DERs and loads to make a uniform and confined structure where the C-MG boundaries (network, market operation, functionalities, business model) and responsibilities of entities/involved parties are well defined. Regarding this, communitybased microgrid structures depending upon the DER/grid integration, control and the location of generators, loads, and prosumer interaction have been reviewed and discussed in this section.

\subsection{General Structures}

Depending upon the control strategies, in general, microgrid structures are defined as centralised, decentralised and distributed systems. A centralised structure is defined as one where single/multiple household and business networks jointly own or engage in an energy project and the whole power and energy management system are controlled centrally. The distributed structure is defined as a network of end-users that produce or own 
distributed generation on an individual basis, are physically or virtually linked through a governing/control body, and operate under the same regulations for providing and consuming energy within the network. Communication among the assets is an important part of the success of this distributed structure. Individuals, businesses, communities or a whole city may form a decentralised system, which can function as a cell that generates and consumes energy locally to secure the energy of their own critical infrastructure during any contingency. Individual assets / cells may not communicate with each other, but response depends on the local point condition. This section reviews the existing structures that are already presented in different pieces of literature and proposed some more structures.

\subsubsection{Centralised Structure}

A centralised structure features a central control of single/multiple DERs that supplies the energy to loads in the vicinity. It has a high level of cohesion and the participants are bound to achieve common goals. Operation and control activities in the centralised structure are largely managed by the central governing body (can be aggregator or collectively nominated by the third party). Studies have found that community-based projects should be built upon sharing common goals, equal welfare distribution and mutual interaction to empower the community [35].

A centralised structure facilitates these objectives, but interaction among the prosumers is very little, as the system is controlled and managed centrally. Broadly, there can be two sub-categories in the centralised structure:

C1: Single central DER, dispersed loads

This category contains a structure in which a DER is centrally located and the loads are in the vicinity of the central DER. Examples include centralised DERs (RES, ESS) supplying energy to individual household loads interfaced with a converter [36,37].

C2: Central group of DERs, a single group of loads

In this category, there can be multiple DERs connected centrally and supplying energy to collective loads in the vicinity. Examples include sets of PV panels and ESS supplying energy to specific loads (emergency, auxiliary) in the room/house/building/community [36]. However, in both of these categories, it must be ensured that the DERs and loads are not located distantly so that the system losses can be minimised and network efficiency can be maintained [36,38].

\subsubsection{Distributed Structure}

The distributed structure comprises entities that may or may not be in close proximity either from the geographical location or their mutual interaction point of view [39]. According to the physical connections in the electrical network, the distributed structure can further have three sub-categories:

\section{D1: Group of distributed DERs, scattered loads}

In this category, a collective group of DERs connected in a distributed fashion will supply energy to the respective individual loads. The DERs themselves do not have to be in close proximity but they do have to remain close to the consumption point or loads. This structure is more suitable for C-MGs, where a group of DERs can deliver energy to the individual households/neighbourhoods [36].

D2: Distributed individual DERs, scattered loads

This subcategory includes a structure in which DERs are distributed independently of each other but supply loads in their vicinity [36,38]. It can facilitate energy exchanges within a home (DER to household load) or neighbouring homes. This type of structure will increase community engagement and market-based participation $[37,40]$.

D3: Group of distributed DERs, group of loads

In this category, collective DERs connected in distributed supply energy to a cluster of loads. DERs are allowed to communicate themselves for better resource allocation for a given instance. It can be a complex structure to design, but it brings better coordination 
among the DERs and customers [40,41]. DERs are solely responsible for meeting the required load demand and maintaining reliability; therefore, it is a crucial task [41].

In a distributed structure, members of the community make their investment plans and decisions depending upon their financial situation and personal preferences. However, the members are connected and controlled through a network management entity (aggregator/or third-party agent) to coordinate, control and manage the community energy network and consequently distribute the benefits equally among all. Therefore, this structure allows community members to participate based on their preferences and makes the overall community active. This structure, however, requires a high level of coordination among members, technology platforms and other entities to efficiently manage the energy and financial transactions.

\subsubsection{Decentralised Structure}

The decentralised structure is different from the centralised and distributed structure in terms of its self-sufficiency and capability of self-governance from the centralised structure. Community members of a decentralised structure can own DERs individually or collectively in a group and can also be bound to a locality, village/town or neighbourhood forming a community microgrid or integrated community energy system $[19,41]$. This can further be sub-categorised as follows:

DES: Single decentralised structure

The single structure includes a combination of the centralised and distributed structures enclosed in it. This subcategory of decentralised structure has a range of possible combinations that can satisfy the emerging community microgrid requirements. Community members will have broader space to share the resources, and larger community interaction is possible [41,42].

\section{DEM: Multi decentralised structure}

The multi decentralised structure has various single structures enclosed in it, thereby forming a cluster of single decentralised structures. Collectively, a single cluster brings complexity but improves the level of reliability and security [42]. The highest level of community engagement is possible, and suitable market structures with specific objectives will also be required to facilitate safe and reliable energy transactions [43].

The decentralised structure relies on strong cohesion and participation with a shared vision of strengthening the community actions to achieve the valuable targets. The structure formation comes with the establishment of new infrastructure or reconfiguration of existing ones carefully planned considering the interests of community participants and other key stakeholders. A high degree of coordination and management will be needed to have effective design and optimal operation. All potential C-MG structure configurations are depicted graphically in Figure 4.

In order to better comprehend the benefits and drawbacks of each structure, Table 2 summarises them all. The next section reviews all three main structures and discusses the potential C-MG structures for controlling DERs and loads. In a centralised structure, category $\mathrm{C} 1$ has less complexity and can be easily implemented [36]. However, the DERs are likely to have a monopoly while the community engagement can be very low [36,37]. In contrast, category $\mathrm{C} 2$ is more complex compared to $\mathrm{C} 1$ but has other features, such as easy scalability, the possibility of lower monopoly and more community engagement compared to $\mathrm{C} 1[36,38]$. In the distributed structure, D1 follows almost similar attributes compared to $\mathrm{C} 2$ except for the difference in the structural design [36]. D2 on the other hand appears to be less complex, with scalability features and lower DER monopoly and a moderate level of engagement among community members $[37,38,40]$. However, D3 is a promising structure in a distributed paradigm, as it is highly scalable, has low DER monopoly and has more peer engagement except for its high complex implementation design [40,41]. DES, which is a single decentralised structure has the advantage over D3 in two attributes, scalability and level of community engagement [41,42]. On the other hand, DEM has multiple DES and is the most advanced structure. Although complexity is very high in terms of scalability, 
and community engagement, it greatly exceeds that of any of its predecessors. Since the community engagement is highest, the DER monopoly is the lowest compared to all the categories $[42,43]$.

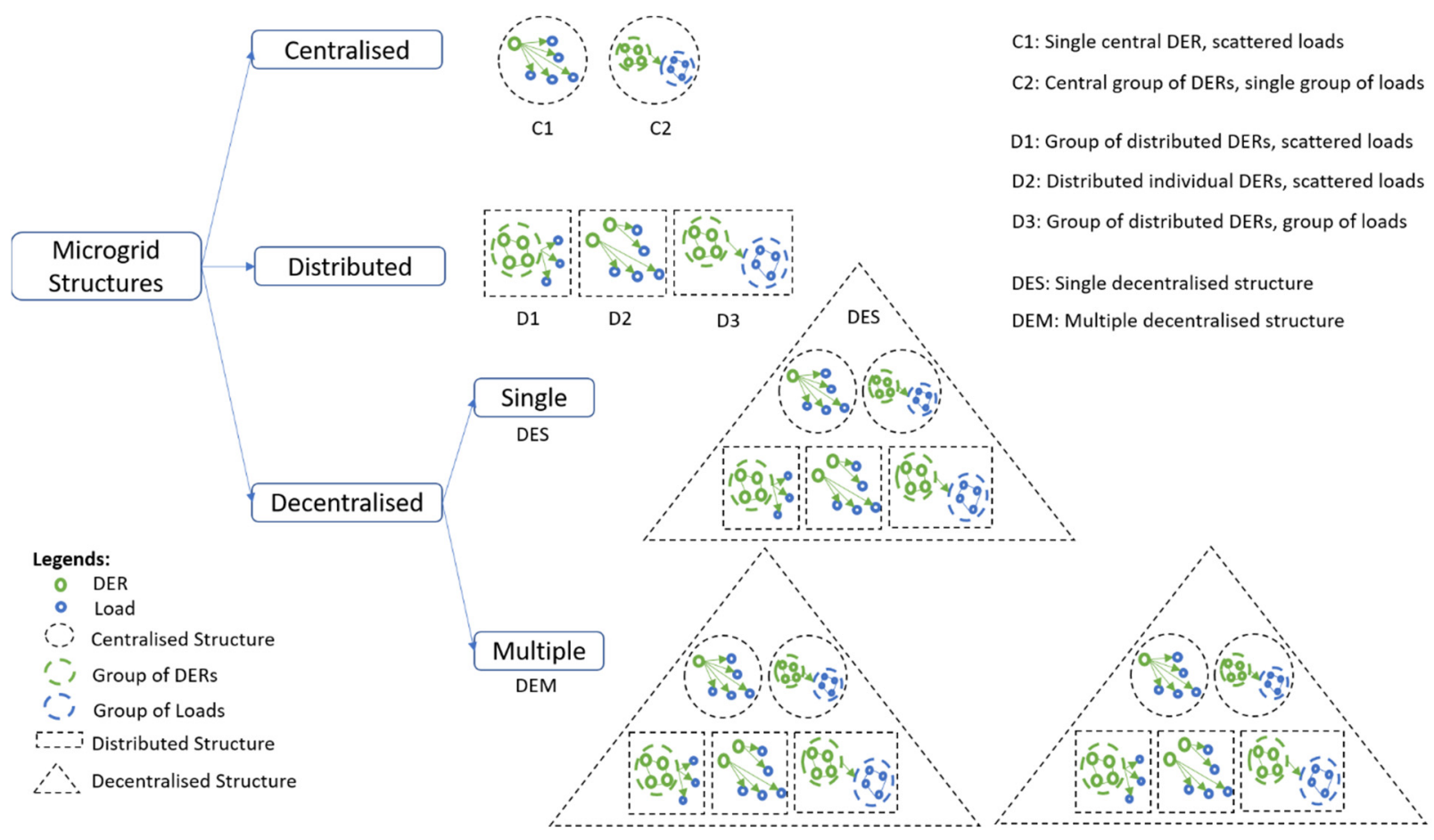

Figure 4. Suggested microgrid structures.

Further, as shown in Figure 5, suggested microgrid structures can be compared based on complexity, scalability, DER monopoly and level of community engagement, given the score as the possibility of Very Low/Possible/Comparatively More/Highly Possible. Complexity means installations of MGs with the involvement of different actors in planning, implementation and different operational stages [44]. Scalability is defined as alteration/up-gradation in system design by anticipating energy requirements to accommodate new changes in such a way to benefit all the community members [45]. DER monopoly refers to the tendency of DER owners who can govern/control the dispatch and retail of energy [46]. Bad governance can impact the cost and benefits of community microgrid operation [46]. Level of community engagement means the participation of community members/entities to cooperate for the management and operation of microgrids, including the selling/purchase of energy $[47,48]$.

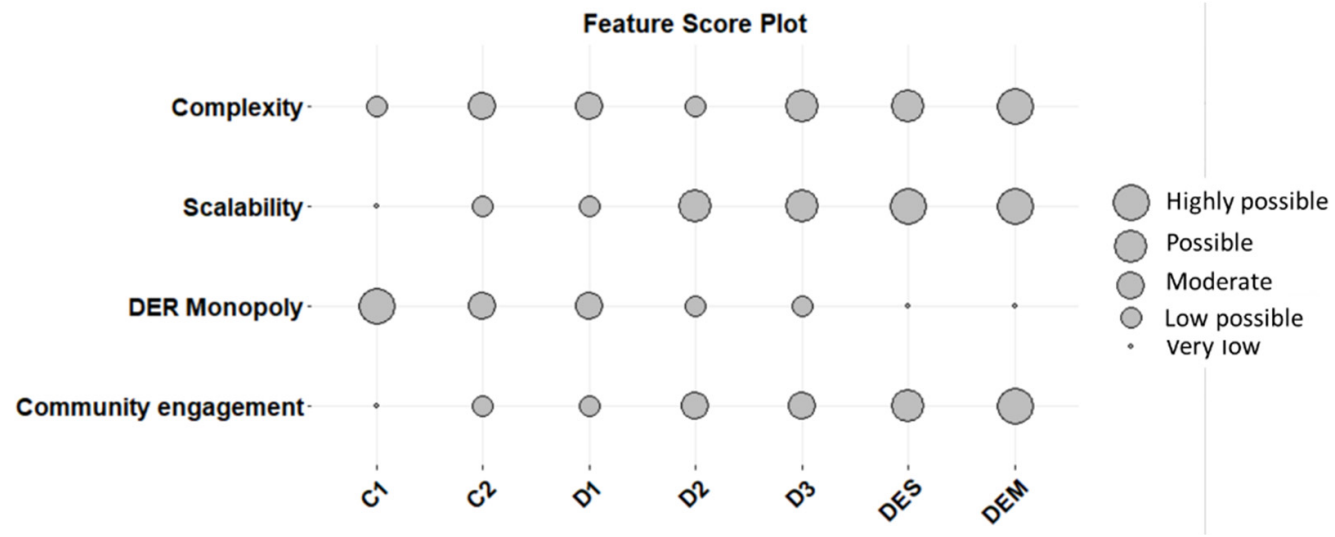

Figure 5. Comparative plot for different C-MG approaches. 


\subsection{C-MG Structures Based on DER Integration}

Numerous variations of the C-MG design have been reported based upon various factors, such as DER integration, converter configuration, feeder connection, location of smart meter, ESS placement, etc. Considering the consumers' active participation in the energy transition and future participation in the energy markets with maximising their clean energy self-consumption and sharing within the community and beyond, it is one of the most important issues to place the DERs near the consumers' premises. Hence, within the community, how the DERs are integrated to form the C-MG networks is also important. Very few articles have discussed this DER integration and C-MG design issues considering future participation in the energy market. Figure 6 shows different C-MG structures that depict the number of connections based on where the DERs (most importantly RES and ESS) are located and how these are connected to form a C-MG network. There are several possible C-MG combinations, which are all listed in Table 3 along with their advantages and disadvantages.
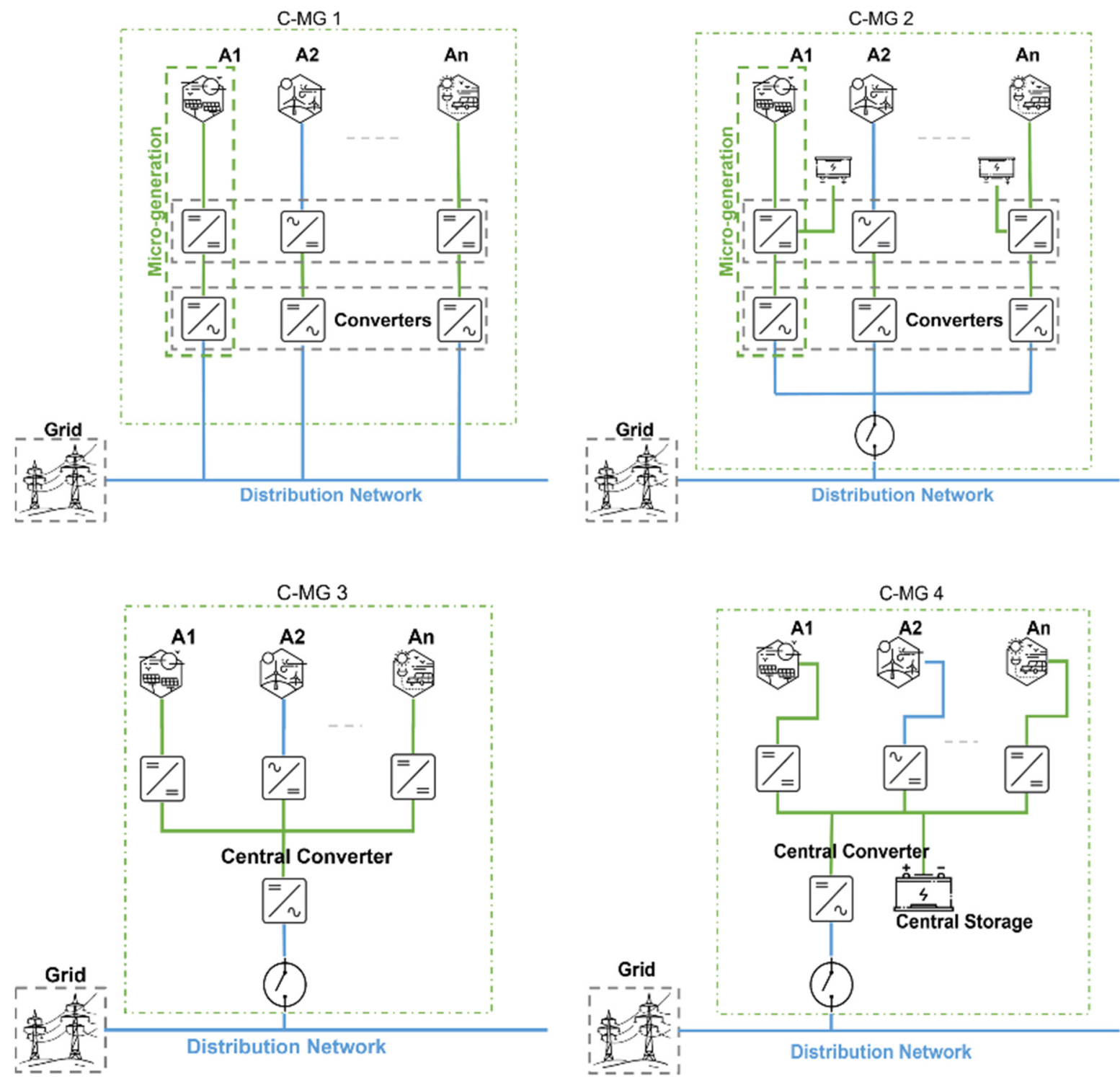

Figure 6. Cont. 

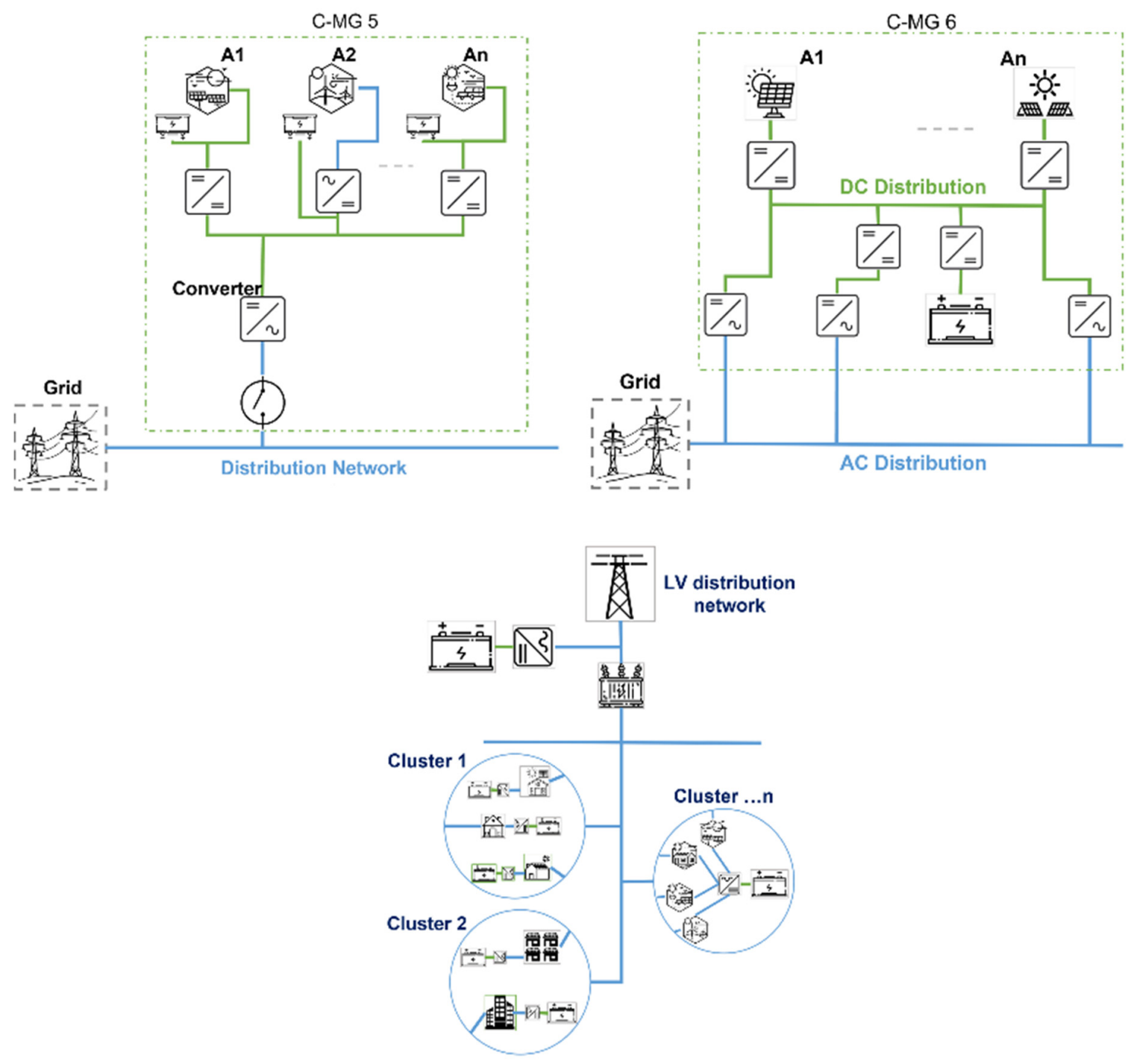

Figure 6. Different C-MG structures based on ESS and DER connection.

Table 2. Pros and cons of the C-MG structures reviewed in Section 4.

\begin{tabular}{|c|c|c|}
\hline Structures & Advantages & Disadvantages \\
\hline Centralised & $\begin{array}{l}\text { Easy integrability with } \\
\text { existing infrastructures } \\
\text { - } \quad \text { Technological readiness }\end{array}$ & $\begin{array}{l}\text { - } \quad \text { Community cohesion required } \\
\text { comending on the DERs integration, } \\
\text { less active }\end{array}$ \\
\hline Distributed & 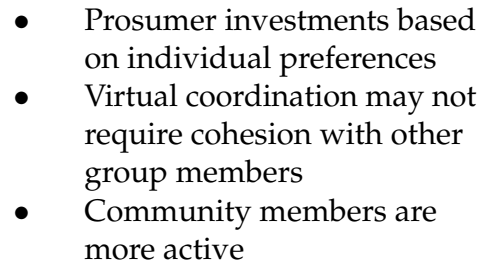 & $\begin{array}{l}\text { - New infrastructure requires for the } \\
\text { virtual hub platform } \\
\text { - Complex coordination and } \\
\text { management }\end{array}$ \\
\hline Decentralised & $\begin{array}{l}\text { Broader energy } \\
\text { infrastructure facilitating } \\
\text { services to several } \\
\text { community members } \\
\text { - High level of member } \\
\text { participation sharing a range } \\
\text { of objectives }\end{array}$ & $\begin{array}{l}\text { A large investment is required for } \\
\text { specialised technology and service } \\
\text { providers to develop new } \\
\text { technological platforms } \\
\text { Difficult to achieve coordination } \\
\text { among a variety of stakeholders }\end{array}$ \\
\hline
\end{tabular}


Table 3. Summary of different C-MG architecture based on DER connection.

\begin{tabular}{|c|c|c|}
\hline Type [Ref] & Advantages & Disadvantages \\
\hline C-MG1 [35] & $\begin{array}{l}\text { Consumers in the community } \\
\text { with individual and completed } \\
\text { micro-generation systems can } \\
\text { form this C-MG. } \\
\text { - } \quad \text { imple design, as each converter } \\
\text { accounts for individual DER. } \\
\text { - Consumers can easily install ESS } \\
\text { at their premises. } \\
\text { The individual has the flexibility } \\
\text { to sell electricity to its own } \\
\text { desirable capacity. } \\
\text { Possible to independently } \\
\text { participate in the local electricity } \\
\text { market. }\end{array}$ & $\begin{array}{l}\text { - As the individual } \\
\text { micro-generation systems are } \\
\text { always connected to the grid, a } \\
\text { virtual C-MG can be formed. } \\
\text { The formation of a real } \\
\text { microgrid would be } \\
\text { difficult/not possible [8]. } \\
\text { Due to multiple small inverters, } \\
\text { maintaining power quality in } \\
\text { the distribution network could } \\
\text { be challenging. } \\
\text { May not be a good option for } \\
\text { apartment buildings, as the roof } \\
\text { space is limited and each } \\
\text { household is allowed to occupy } \\
\text { an equal installation area. } \\
\text { Not likely for commercial use } \\
\text { (households/apartments with } \\
\text { low daytime loads will export } \\
\text { much of their generation to the } \\
\text { grid and disparity among } \\
\text { consumers). } \\
\text { Less connected/communicated } \\
\text { with the community neighbours. } \\
\text { among the group. }\end{array}$ \\
\hline C-MG2 [35] & $\begin{array}{l}\text { Consumers in the community } \\
\text { with individual and completed } \\
\text { micro-generation systems can } \\
\text { form this C-MG. } \\
\text { - } \quad \text { imple design, as each converter } \\
\text { accounts for individual DER. } \\
\text { All/some of the consumers } \\
\text { must have ESS at their premises. } \\
\text { Depending on the control, can } \\
\text { work in isolated mode. } \\
\text { The individual has the flexibility } \\
\text { to sell electricity to its own } \\
\text { desirable capacity. } \\
\text { Compare to C-MG1, consumers } \\
\text { are more } \\
\text { connected/communicated with } \\
\text { the community neighbours. } \\
\text { - Consumers can be interactive } \\
\text { among the group. } \\
\text { Possible to independently } \\
\text { participate in the local electricity } \\
\text { market. } \\
\text { services. }\end{array}$ & $\begin{array}{l}\text { A real C-MG can be formed but } \\
\text { requires advanced smart } \\
\text { metering, coordination and } \\
\text { control of the inverters. } \\
\text { Due to multiple small inverters, } \\
\text { maintaining power quality in } \\
\text { the distribution network could } \\
\text { be challenging. } \\
\text { May not be a good option for } \\
\text { apartment buildings, as the roof } \\
\text { space is limited and each } \\
\text { household is allowed to occupy } \\
\text { an equal installation area. } \\
\text { Not likely for commercial use } \\
\text { (households/apartments with } \\
\text { low daytime loads will export } \\
\text { much of their generation to the } \\
\text { grid and disparity among } \\
\text { consumers). }\end{array}$ \\
\hline
\end{tabular}


Table 3. Cont.

\begin{tabular}{|c|c|c|}
\hline Type [Ref] & Advantages & Disadvantages \\
\hline C-MG3 [36] & $\begin{array}{l}\text { Multiple DERs connected to the } \\
\text { grid through a single centralised } \\
\text { inverter. } \\
\text { - Can improve the power quality } \\
\text { further compare to C-MG1 and } \\
\text { C-MG2. } \\
\text { Due to a single large and } \\
\text { centralised inverter, the system } \\
\text { cost reduces. } \\
\text { Can be a good option for } \\
\text { apartment buildings where } \\
\text { consumers integrate their DERs } \\
\text { through a single converter. }\end{array}$ & $\begin{array}{l}\text { - Needs advanced smart metering, } \\
\text { control and coordination with } \\
\text { DERs and consumers. } \\
\text { - Failure of the central converter } \\
\text { can affect the entire MG. } \\
\text { - Can't be operated as an islanded } \\
\text { microgrid. } \\
\text { Reduces the consumers' active } \\
\text { participation and energy trading } \\
\text { flexibilities. }\end{array}$ \\
\hline C-MG4 [36] & $\begin{array}{l}\text { Multiple DERs can be connected } \\
\text { through a single centralised } \\
\text { inverter and store energy in a } \\
\text { single ESS unit. } \\
\text { Comparatively easy to control } \\
\text { and operate. } \\
\text { Further improvement of } \\
\text { previous structures. with a } \\
\text { possibility to operate in islanded } \\
\text { conditions as well, when } \\
\text { needed. } \\
\text { Increase the consumers' active } \\
\text { participation and energy trading } \\
\text { flexibilities. } \\
\text { Can provide further support to } \\
\text { improve the grid stability and } \\
\text { power quality. }\end{array}$ & $\begin{array}{l}\text { - Needs advanced smart metering, } \\
\text { control and coordination, and } \\
\text { communication with DERs and } \\
\text { consumers. } \\
\text { - Failure of the central converter } \\
\text { can affect the entire MG. }\end{array}$ \\
\hline C-MG5 [35] & $\begin{array}{l}\text { Embedded network with } \\
\text { common DC link and multiple } \\
\text { ESS at consumers' premises. } \\
\text { and grid-connected through a } \\
\text { single centralised inverter. } \\
\text { Due to the presence of multiple } \\
\text { ESS, operation as an islanded } \\
\text { microgrid is possible. } \\
\text { Consumers can engage and } \\
\text { participate in the market } \\
\text { collectively. }\end{array}$ & $\begin{array}{l}\text { High retrofitting (system } \\
\text { integration) costs } \\
\text { The administrative burden } \\
\text { associated with retailing energy } \\
\text { to residents. } \\
\text { - Failure of the central converter } \\
\text { can affect the entire MG. }\end{array}$ \\
\hline C-MG6 [35] & $\begin{array}{l}\text { Embedded network with } \\
\text { - Common DC link and single ESS. } \\
\text { Can effectively accommodate } \\
\text { future DER installations. } \\
\text { - Consumers can engage and } \\
\text { participate in the market } \\
\text { individually. }\end{array}$ & $\begin{array}{l}\text { High retrofitting (system } \\
\text { integration) cost. } \\
\text { The administrative burden } \\
\text { associated with retailing energy } \\
\text { to residents. }\end{array}$ \\
\hline C-MG7 & $\begin{array}{l}\text { Multiple clusters based on } \\
\text { C-MG1 to C-MG6 can be } \\
\text { coordinated and operated } \\
\text { together within a community. } \\
\text { - } \quad \text { Local energy trading is possible. } \\
\text { Consumers can be more active } \\
\text { and engaged. } \\
\text { Different control mechanisms } \\
\text { can work together. }\end{array}$ & $\begin{array}{l}\text { - Complex control \& operational } \\
\text { arrangements. } \\
\text { Different load profiles can make } \\
\text { it difficult to share the benefits } \\
\text { gained from the market equally. }\end{array}$ \\
\hline
\end{tabular}




\section{Interoperability}

Interoperability represents the ability to exchange information in a timely and actionable manner, and, although this aspect is critical, it has not been in the focus of most of the recent smart grid research. Grid modernisation has been extensively progressing in recent years, but the production of technology and associated standards have only modestly improved interoperability [49]. The state of the art of the interoperability issues is not well discussed and standardised for the MGs/C-MGs. This section attempts to establish a correlation between current power system standards and the limits imposed by interoperability difficulties in C-MG. The connectivity of C-MG and SGAM architectures are also proposed through the interoperability layer.

Divergent and convergent factors may be found on the route to interoperability. On the one hand, bottom-up microgrid structures are set up by different stakeholders getting help from specific manufacturers, which may or may not use open standards [50]. While proprietary solutions might serve the purpose of a particular implementation, the lack of interoperability often forms a blocking factor for maintaining, extending or replicating the microgrid architecture. When non-proprietary solutions are chosen, there is often a multitude of standards to choose from: some standards come from the power system domain, others from the communication domain, and others from home automation systems or smart energy applications. Especially if existing assets are integrated into microgrids, wrappers need to be added to translate protocols into other protocols and to ensure a certain level of interoperability between different assets from different developers, to allow a microgrid to function. Similar protocol-to-protocol translations and custom-built interfaces emerged, e.g., when small DSOs (distribution system operators), each with their own vendor-specific SCADA systems (supervisory control and data acquisition systems) merged into bigger ones, where a unified supervisory control application needs to become operational. Having such a multitude of protocols and APIs-with all types of one-to-one translations-is not the way forward for a wide deployment of microgrids. A structured, interoperable approach is needed to mitigate this divergence.

On the other hand, top-down authorities and policymakers try to funnel the different approaches and to harmonise the standards, to converge the protocols and infrastructures that are used, and this is without influencing markets. In smart grids, this has been driven to a large extent by the CEN/CENELEC/ETSI Smart Grid Coordination Group, in which three standardisation organisations are active (generic-CEN, electrical-CENELEC and communication oriented-ETSI). They published the "Smart grid reference architecture" [22] as a framework for interoperability (with the SGAM model mentioned earlier) in November 2012. The European Commission has an even longer history of calling to action the different involved standardisation organisations to set forward best practices and guidelines towards interoperability. Similarly, The Institute of Electrical and Electronics Engineers (IEEE) develops Standard such as IEEE 1547, which is the foundational document for the interconnection of DERs with the grid. With the recent advancement of modern power system solutions to enhance the integration of DER and loads with the smart grid intelligence, IEEE 2030 informs the grid interoperability issue to achieve the greater implementation and visualisation of information and communication technologies [51]. Table 4 summarises the key issues that are addressed in the interoperability-related standards.

An overview of all related smart grid standards is maintained by the IEC (International Electrotechnical Commission) as an interactive map linking to all underlying standards, as indicated in Figure 7 below. 
Table 4. List of standards related to interoperability.

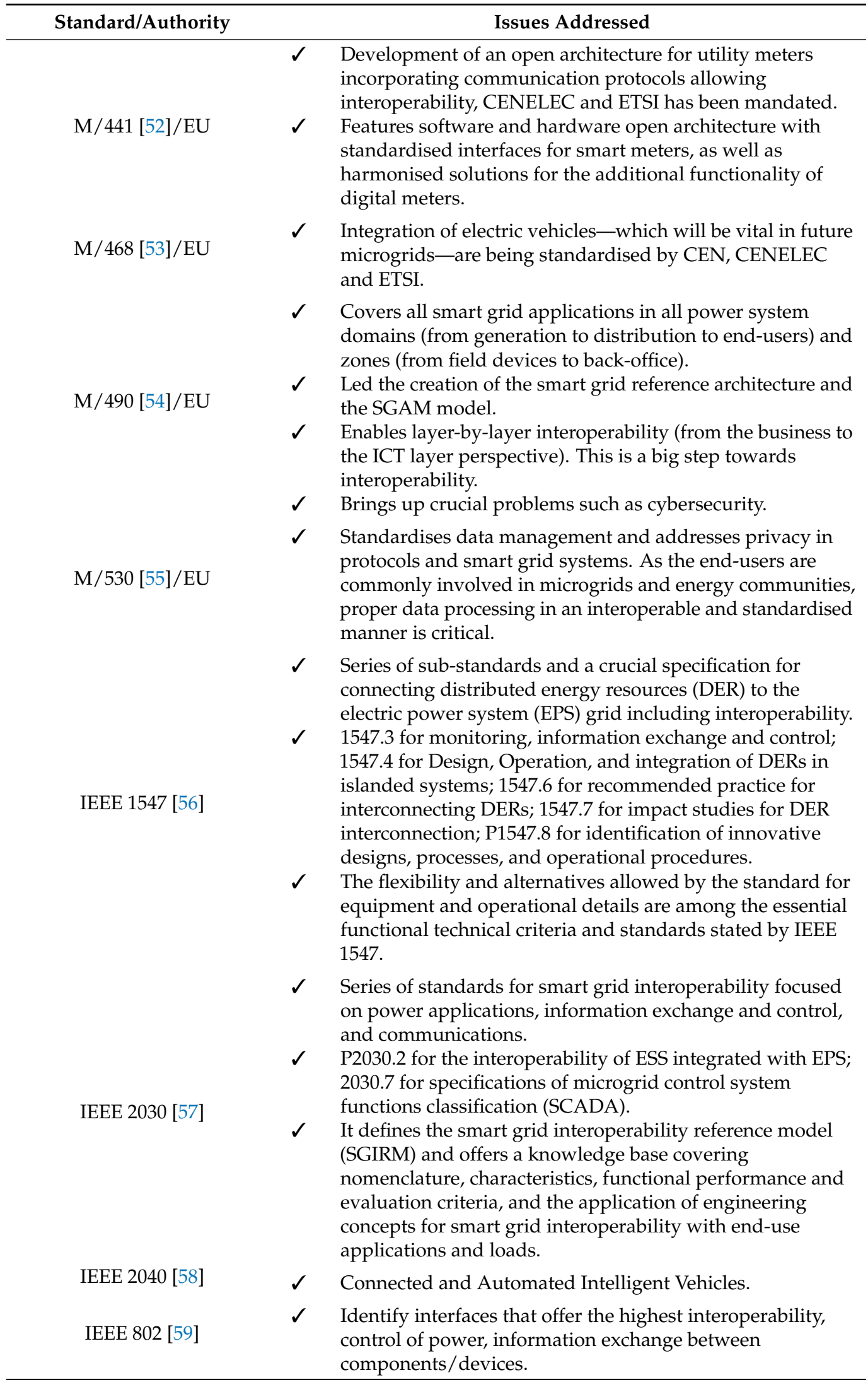


Table 4. Cont.

\begin{tabular}{ccl}
\hline Standard/Authority & \multicolumn{1}{c}{ Issues Addressed } \\
\hline IEC 61850 [60] & $\checkmark \quad \begin{array}{l}\text { Communication in substations includes all protection, } \\
\text { control, measurement and monitoring functions, and } \\
\text { additionally provides the means for high-speed substation } \\
\text { protection applications, interlocking and inter tripping. }\end{array}$ \\
$\qquad \begin{array}{l}\text { Energy management system application program interface } \\
\text { (EMS-API), common information model (CIM), important } \\
\text { for microgrid and its interconnection with the smart grid } \\
\text { network. } \\
\text { IEC 61970 [61] }\end{array}$ \\
$\qquad \begin{array}{l}\text { Framework for energy market communications, CIM } \\
\text { extensions for markets. }\end{array}$ \\
\hline
\end{tabular}

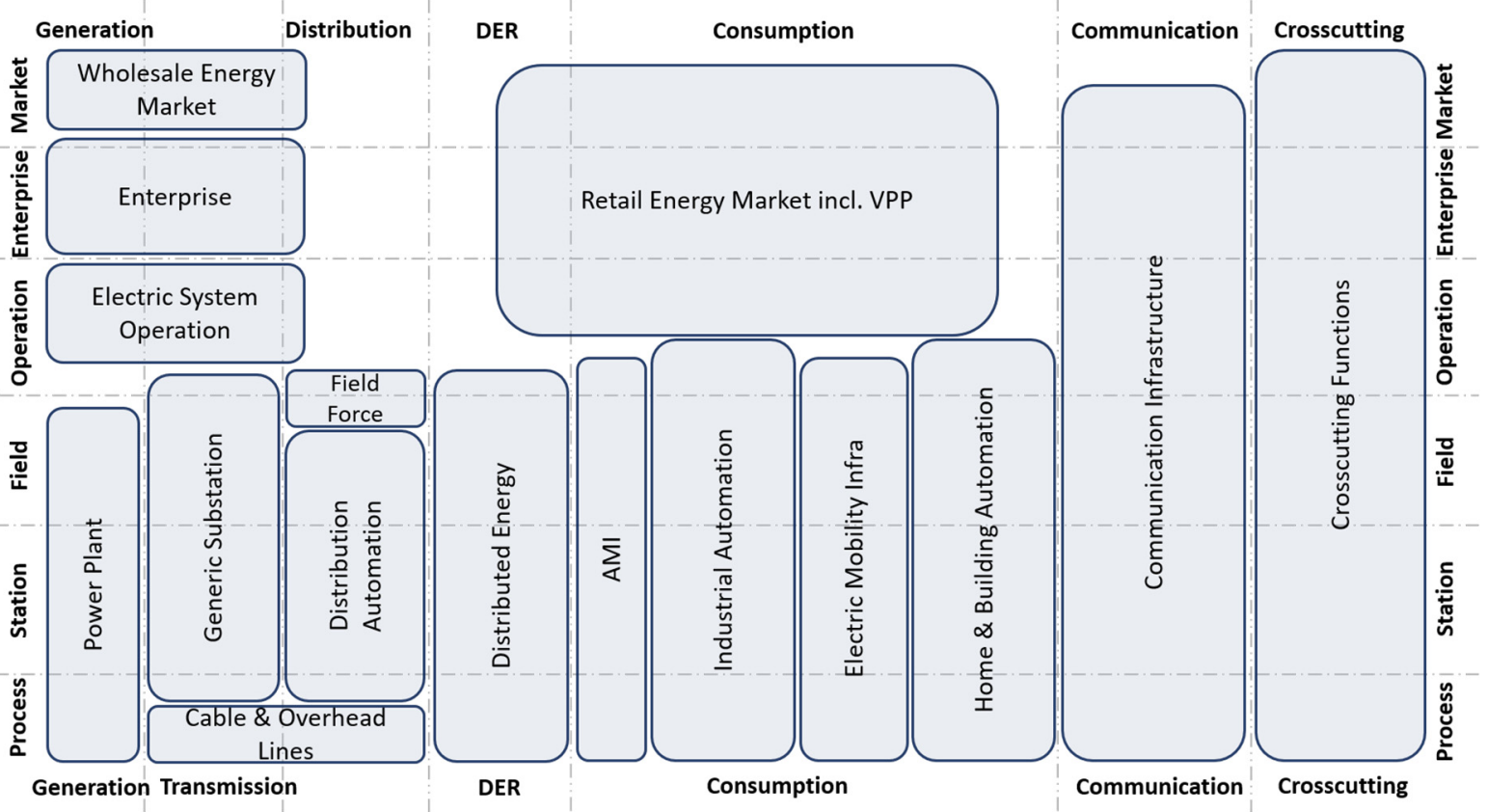

Figure 7. IEC interactive map on smart grid standards [62].

Going down to the level of microgrids and energy communities, it is also recommended to take these standardisation and harmonisation approaches into account and to adopt an open system philosophy, because the future proofness of standardised solutions often outweighs the slightly better performance of proprietary solutions, due to the limitations from vendor lock-in. Obviously, during proof-of-concept studies and research demonstrations of microgrid architectures, standardised and interoperable setups are not often a primary concern. Nevertheless, interoperability and standardisation are critical for having a good replication potential and for upscaling microgrids in wide deployment.

Microgrids with a wide range of interoperability capabilities will enhance the operation and control of the overall system [63]. However, the full interoperability issues that affect the grid have not been completely explored in the microgrid context. Interoperability issues can directly impact grid resiliency and the reliability of the MGs. Accountable information related to the interoperability concerns between systems and components that originated at the physical layer must be followed up by the entity responsible for controlling both the microgrid and the external grid [64]. The added advantage of good interoperability would be that it can facilitate a trading mechanism for resiliency-enhancing services between affected and unaffected domains. Better information sharing would allow for faster response times and quicker restoration of services [64]. Interoperability will 
improve the overall coordination to supply the residual loads at the edge locations [64]. Rapid integration of DERs in the microgrid brings a challenge for utilities in terms of maintaining the reliability of the system in what-if scenarios such as what would happen if the entire microgrid goes down. In addition, interoperability facilitates enhanced decentralised control. However, it depends upon the utilities and how they adopt the better interoperability framework to understand the predictability of DERs and minimise adverse impacts on the main grid [49].

Further, interoperability is considered to be the most important feature for the development of the smart grid. As a consequence of this, the proposed SGAM architecture also addresses interoperability. Definition and prerequisites for attaining interoperability are provided in Figure 8, for understanding interoperability in the context of smart grid and architectural models. This framework validates smart grid use cases and supports them with standards, which is in line with the M/490 initiative.

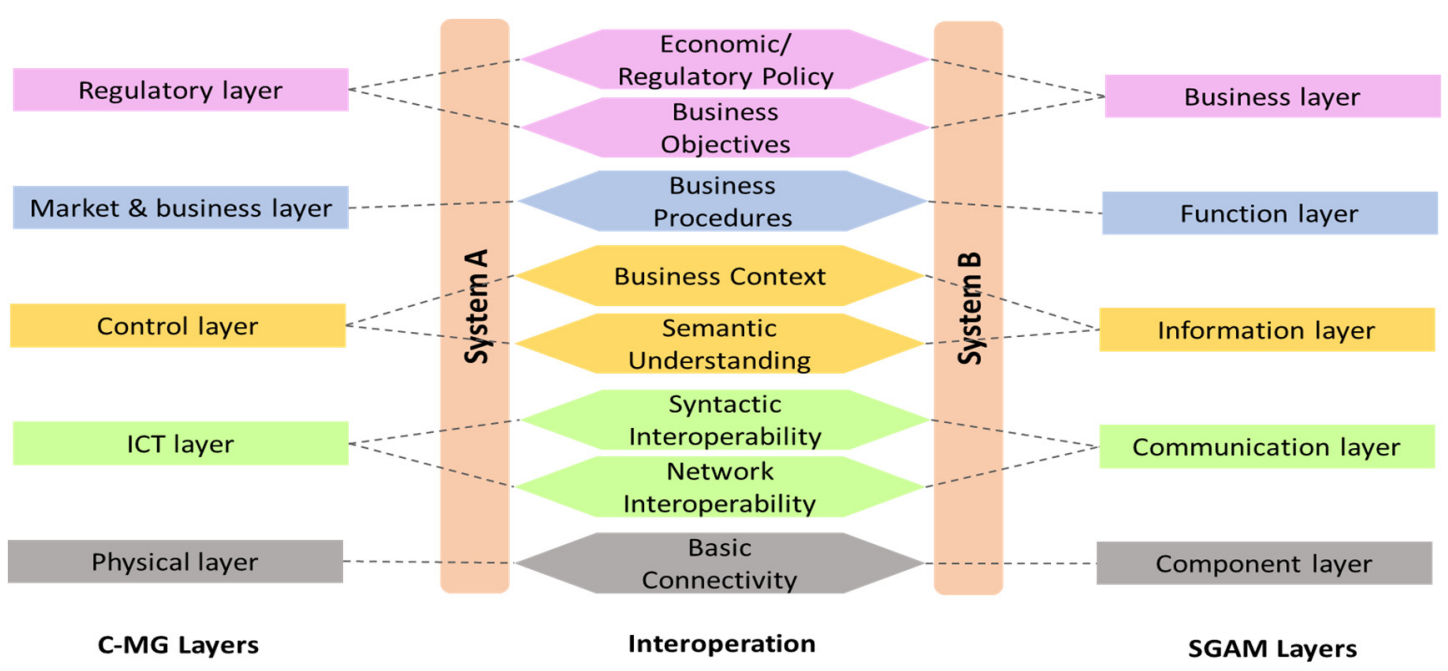

Figure 8. Proposed connectivity of C-MG and SGAM layers through the interoperability mechanism.

In the proposed architecture, the regulatory layer reflects the corporate perspective on the information exchange connected to smart grids. In addition, this layer of SGAM may be used to map the regulatory and economic (market) frameworks and regulations, as well as the new business models. The market and business layers, on the other hand, were depicted as being separate from actors and physical implementations in applications, systems, and components. It assists market operators in making judgments about new business practices for LEM (P2P) energy trading. Data communication between functions, services, and components of SGAM is handled by the proposed control layer. The data model developed in the control layer is responsible for the interoperable information exchange through the ICT layer. ICT layer employs communication channels for interoperability between components in the context of the underlying use case, function or service and the corresponding information objects or data models. Finally, the physical layer uses the existing smart grid infrastructure (including power system equipment, protection devices, communication channels, etc.) for participating in interoperability operations.

\section{Market Integration}

In relation to consumer engagement and community market participation, the local energy/electricity market (LEM) can be defined as a socially close community of residential energy-active users (prosumers, consumers) that have access to a joint market platform for trading self-produced energy/electricity among themselves. The mechanism may support the consumers/communities to participate in the wholesale electricity market (WEM) in the future. Such consumer/community-centric markets can be classified as (i) peer-topeer markets (P2P), an online platform where active consumers and producers "meet" 
to trade electricity directly, with/without the need for an intermediary, (ii) transactive energy markets (TE), a set of mechanisms where economic-based instruments are used to achieve a dynamic balance between the generation and consumption without violating the operational constraints of the power system, and (iii) community self-consumption (CSC), a framework that facilitates the sharing of clean electricity generation within a community to achieve collective self-sufficiency. The physical community energy system can be connected to the distribution network or can form an isolated network. In these cases, they can also operate as virtual or physical microgrids.

The consumer-centric P2P energy trading (without any aggregator) mainly depends on decentralised C-MG architecture, where all peers cooperate according to the energy availability and economic structure, which eventually ensures the consumer's flexibility. The community-based P2P energy trading mainly depends on community economic structure and regulation. However, lots of research projects and campaigns are initiated to encourage consumers to participate in this future market transition. Most of the countries still have regulatory constraints for consumer-centric energy trading. One of the most important reasons is that analysing the impact of LEM on the distribution network is still in its early stages. Reviewing the literature shows that most of the studies are based on theory and simulation, some have lab-scale experimental validation and very few are known from the real-world demonstration [65-67]. None of the reviewed articles yet concentrate on the system integration level (within the physical layer), where it can be shown that the different integration methods of DER (as shown in Figure 6) could reduce the grid impact. The current concerns for implementing the new energy market models are legal and regulatory issues, potential grid congestions, cyber threats, consumer engagement, and the poorly designed market structure. In the following section, the potential constraints for developing a consumer/community-centric market model are briefly reviewed.

\subsection{Prosumers beyond Self-Consumption}

Engaging the consumers and adjusting their random behaviour is a huge challenge for new energy solution implementation. Smart grid technologies are often conceived, designed, and developed without the end-user being the central concern. This leads to poor participation and engagement from the communities using it or further developing it [68]. Consumer demand for the sourcing of local electrical energy and the potential barriers to a trusted and open energy market is a widely raised research question [69-71].

Research has shown the socio-technical and economic impact potential resulting from increased prosumer engagement in the community and local energy markets. Such markets have the potential to:

- Trigger local sustainability projects that drive energy independence, reduce emissions, reduce fuel poverty and generate local jobs [72].

- Encourage investment in new projects by increasing democratic control over energy investments [73]. This can increase the acceptance of RES installations and simplify the planning process in communities.

- Generate financial returns by creating a mechanism for reinvestment or reallocation of energy revenues directly in host communities, for example, by profit sharing or dividends.

- Mobilise citizens by enabling joint action for addressing local issues, for example, climate change or air pollution.

- Increase the visibility of energy use among consumers, thereby driving the uptake of energy efficiency measures.

- $\quad$ Reduce energy costs and lower network tariffs, as well as improve fairness in relation to the socialisation of grid costs [74].

- Improve social cohesion. 


\subsection{Impact of LEM on Microgrids and Possibility to Improve by Integrating It into the Wholesale Market}

LEMs can be used to balance local demand to match intermittent supply, manage congestion and transmission/distribution constraints, support the financial management of participants that takes into account location and network needs and replace/postpone grid investments with the utilisation of local flexibility [75]. Interactions and interfaces between local and wholesale central markets are still undetermined. Therefore, different options for interfaces need to be considered when modelling LEMs. Wholesale aggregators either can operate directly on the local market platform and neutrally offer energy at wholesale market clearing prices, or the LEM is operated by a market operator/C-MG operator/aggregator that competes in the local market and has the opportunity to trade between the local and wholesale markets.

When it comes to P2P-based LEM, agents with intelligence are benefited from the lowest overall average electricity price [76]. The authors in [77] also evaluated the performance of a fully integrated TE-based LEM while modelling the energy resource management problem of a microgrid under uncertainty considering flexible loads and market participation, and coupling these with LEM and WEM. It was concluded that introducing LEM provides an efficient mechanism to reduce costs. An enhanced security management system for LEM is also proposed in [78], where model-based system architecture was designed for an interoperable blockchain-based LEM for prosumers in a residential microgrid setting. It shows the confidentiality and integrity required for energy trading to sustain continued energy supply and sales, the ability to track energy sources during energy generation and energy dispatch so that renewable energies are separately identified from non-renewables, and access for customers to energy data transaction details so that the type of energy provisioned to their premises is known. LEM incorporating multiple energy carriers and bid structures suitable for representing flexibility is also presented in [79]. The incorporation of multiple energy carriers in the market clearing leads to potential synergies and increased efficiency in the use of existing resources. The authors in [80] also discuss a Swiss example of LEM specifically based on P2P energy trading within a regulatory sandbox and investigate a TE system that manages the exchange and remuneration of electricity between consumers, prosumers and the utilities. The smart meters send bids to both consumers and prosumers, which contains the price limit determined by each household. This allows the end-users to be more involved in the market use. However, it was confirmed that the behaviour of peers was not influenced so much by the market prices as it was from personal relationships and friendships. This brief review confirms that the research and demonstration on LEM/WEM market models and their integration have already been established at some level and also included in the microgrid research.

It is also expected that these new LEM models can provide flexibility to all consumers to participate in the power system transition. Where the retail energy market lacks competition, the consumer-centric P2P/TE/CSC-based energy market could be an alternative solution. The IEA task "Global Observatory on Peer-to-Peer, Community Self-Consumption and Transactive Energy Models" [81] is collaborating internationally to understand the policy, regulatory, social and technological conditions necessary to support the wider deployment of P2P/TE/CSC models. It has thus generalised the LEM framework in five layers, which also aligns with the proposed C-MG architectural framework, as shown in Table 5. It is also noted that, in order to facilitate the LEM introduction, this IEA global observatory has come forward with valuable policy recommendations, including the prioritisation of the uptake of advanced metering infrastructure ("smart meters"), allowing consumers to have several energy suppliers at the same time and demand response to compete fairly with storage capacity mechanisms, recognising and enabling community energy groups to become service providers on the grid and reducing social and environmental taxes and charges from consumers' electricity bills. Figure 9 provides an example of possible energy market designs based on the proposed C-MG structures in the previous section (Section 4, Figure 5). In this structure, individual/community-based peers are 
engaged in energy transactions between themselves/communities through the community manager interacting with the designed energy market.

Table 5. LEM layers.

\begin{tabular}{cc}
\hline LEM Layers [65] & Proposed C-MG Layers \\
\hline Physical layer & Physical layer \\
ICT layer & ICT layer \\
Market & Control layer \\
Socio-economic layer & Market and business \\
Policy and Regulatory layer & Regulatory layer \\
\hline
\end{tabular}

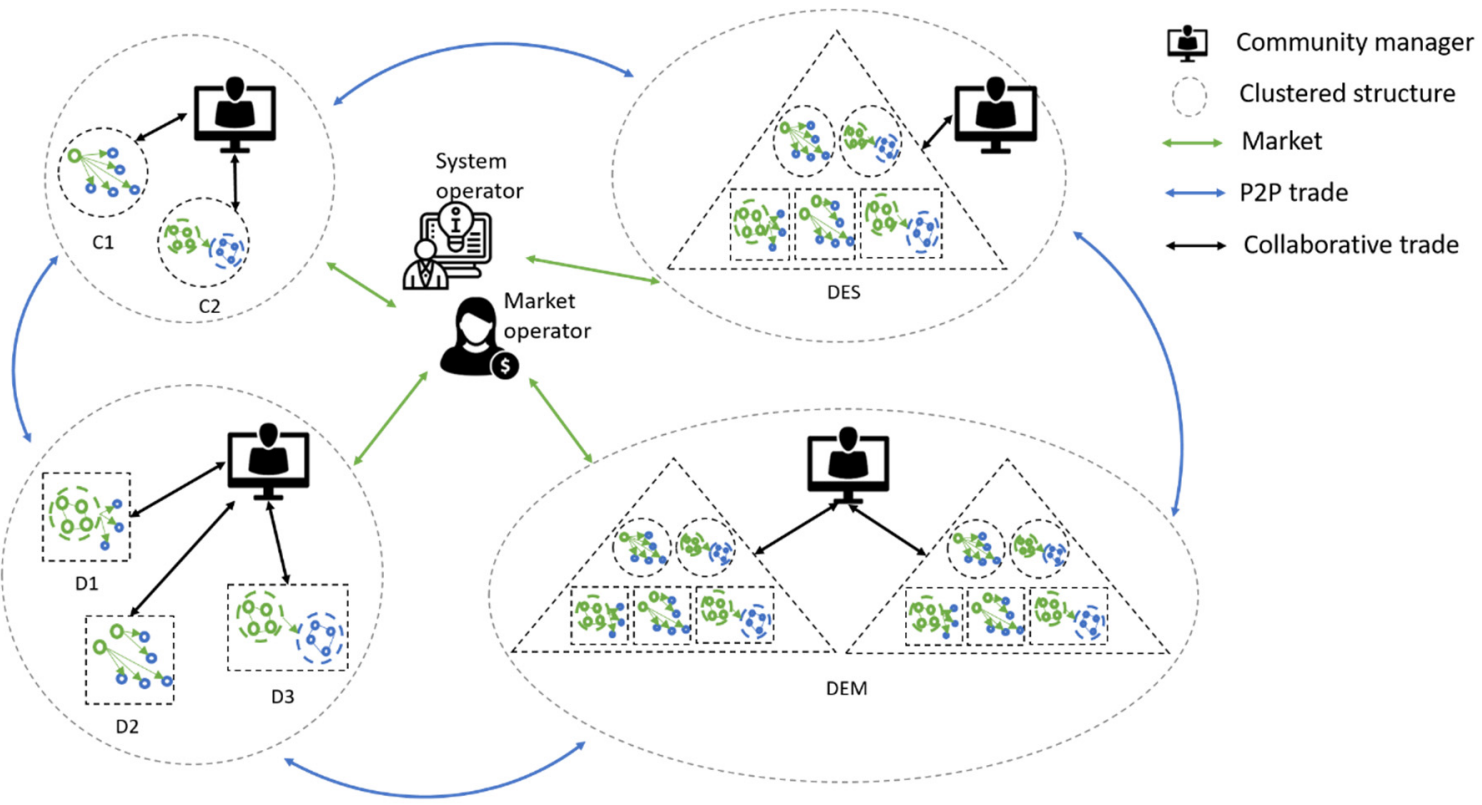

Figure 9. An example of possible market design within different C-MG structures.

\section{Social Aspects}

There is no doubt that the community-based microgrid solutions can not only bring lots of benefits to the community but also support achieving the national clean energy targets, mitigate greenhouse emissions and ultimately provide a healthier environment for society. A recent review of the existing real-life C-MG demonstration projects [44] finds that while utilities are playing a central role in developing the C-MGs, creating social capital is critical for the successful implementation of C-MGs. It also often requires a radical change in institutions and special support from the government. Since the structure of C-MGs is technically complex and the development process is somehow challenging, the success depends on the implementer's ability to increase the social value of implementing and operating the C-MGs, which in turn will increase social acceptance. Hence, this study very briefly reviews the literature on the social aspects of the operational phase of C-MGs to give insight into how the local energy communities develop into methods for stakeholder engagement, participation and social acceptance.

Authors in [47] proposed a methodology that is based on the concept of a community as a socio-ecological system affected by the technological intervention. They identify how technology can be accepted when participation and co-design are used in the technological intervention. A four-stage methodology for community engagement is described and is validated by testing in a real-life setting in Chile. The paper describes how participation builds trust and adaptability as well as social learning and reflexivity. 
To quantify the social benefits, stakeholder mapping was also used to match the relevant benefits in [82]. It identifies the multi-objective and multi-stakeholder engagement nature of microgrids and their benefits and the large number of different assumptions that could impact microgrid benefits. The Huatacondo project is demonstrating reallife examples in South American countries located in isolated mountain regions where the community are involved in the operation of the smart grid and participated in its co-design [83]. The positive impact of community participation implies better energy management and economic and social benefits.

The authors of this review paper recognise that the ongoing needs and barriers faced by local energy communities are also complex. Hence, microgrids that were developed and operated through innovative participative methodologies have been given particular attention in this review. Comparisons with the Living Lab approach were considered here to identify the potential for future applied research to find novel ways to address the social problems of C-MGs.

A Living Lab is an innovation intermediary, which orchestrates an ecosystem of actors in a specific region. Its goal is to co-design products and services, iteratively, with key stakeholders in a public-private people partnership and in a real-life setting. One of the outcomes of this co-design process is the co-creation of social value (benefit). To achieve its objectives, the Living Lab mobilises existing innovation tools and methods or develops new ones [84]. The Living Lab Integrative Process involves empathising with users and defining problems, as well as integrating stakeholders using methods such as communitybased social marketing. It is well accepted that the co-design of solutions with users is an important step in the process prior to prototyping and testing. Hence, the literature on microgrids is assessed here to identify the social research methods associated with the development process to help propose how a Living Lab methodology could benefit local energy community operations.

The challenges of energy consumption for end-users in microgrids are described in [85] and help identify that the need to ensure better buy-in at the design and planning stages of project development is important to facilitate stronger social acceptance and cooperation from the outset. It also discusses the consequences and possible scenarios for stakeholder engagement. The Living Lab approach should identify the early participation of users to support co-design and better acceptance and participation in the operational phases.

The local issues / factors also influence the development of local energy systems and include the social aspects. A framework for the design of microgrids including social analysis in a multi-objective way using criteria such as the inhabitants' cost of living and intercultural aspects, instead of traditional technical and economic analysis, is proposed in [86]. The results show how the proposed framework can be applied in a real-life setting and therefore provide useful case scenarios when considering how a Living Lab approach could be used in the development of local energy communities.

Engaging the community in microgrid operation and maintenance (O\&M) is another important issue to explore within the context of the long-term sustainability of microgrids [87]. In this case, the development of business models for covering investment and O\&M costs helps to identify if local stakeholders and social capital are needed. This approach is also presented in [88], where macro and micro levels of analysis and tools are implemented in Living Lab to improve long-term sustainability. However, the need for co-design to involve users in operational phases of Local Energy communities is not specifically identified as a potential way to improve the long-term sustainability of microgrids.

The literature shows a lack of social research on the operational and earlier phases of microgrids and the need for methodologies to better understand the context, needs and barriers faced by the communities, so that successful operational strategies can be implemented and lead to better acceptance, and long-term sustainability of C-MGs. At the same time, the operation of C-MG should technically be supportive to the utilities, so that the smart grid network operators do not face any technical difficulties in maintaining the network stability. 


\section{Findings and Recommendations}

This article contributes to the prospects of the various C-MG architectures based on the operational structure, interoperability, market integration and socio-economic aspect. The pros and cons of different C-MG structures, market operations and the socio-economic effect are reviewed extensively in the previous sections. The overall findings from this review work and recommendations for future work are outlined below to align with the research questions as identified in the methodology, Section 2. Table 6 also provides a summary of findings for different C-MG structures as discussed in Section 4.

- Architectural framework: The review finds that a generalised architecture needs to be developed for microgrids/community-based microgrid solutions so that, in the future, C-MG solutions can easily be integrated with the smart grid network. Hence, the proposed C-MG architectural framework is kept very much aligned with the SGAM layers. In addition, consumers and communities with C-MG solutions will have easy access to, and participate in, the future LEM/WEM, along with their socio-economic benefits. The proposed architecture has a special focus in this direction as well. Future research and demonstration work should focus on all of these dimensions in their studies.

- C-MG Structure: This paper also generalised the C-MG structures first based on the control approach (centralised, distributed and decentralised) and then based on the DER integration. Both issues are very important with respect to utility support, enduser integration, and active participation in the future market point of view. With respect to the main performance criteria, such as complexity, scaling, decentralisation of DERs, and the degree of participation by consumers (prosumers), the decentralised and distributed C-MG approaches could be more supportive for consumers and community engagement, reducing the DER monopoly and easy scalability. On the other hand, these will have more complexity in control and communication along with future WEM participation. Research also requires more attention to increase the advantages in centralised conditions, as it has less complexity in control, comparatively it is more grid supportive/flexible and the social engagement/benefit is also high (C-MG2, 4, 5, 7-as shown in Table 6).

- Interoperability: This is one of the key elements for enabling C-MG solutions in practice. Compared to a decade ago, large steps forwards have been made, partially under the impulse of the European Standardisation Mandates. IEEE and IEC have also come forward. These initiatives have resulted in a clear inventarisation and characterisation of relevant standards and thus provided a path (with the SGAM and C-MG architecture) to discuss interoperability at different levels. Most importantly, the standards do not impose or prohibit any technical solutions from being used but provide a guideline for authorities and incentives involved stakeholders to implement future-proof solutions. This article also shows the initial connectivity of C-MG and SGAM layers through the interoperability mechanism. Literature review finds massive gaps here. Further research is required in this direction.

- Market integration: The proper design of the electricity market with the greater involvement of consumers and the wholesale market is highly recommended for the smooth development of a C-MG. Until now, individual/small-scale P2P energy transitions are restricted, as the existing business models are highly reliant on a centralised pool structure. Proper coordination of LEM and the WEM is required to ensure the consumer takes advantage of the new business model. However, consumer-centric P2P energy trading is a great concern for potential grid congestion. The new business model should deeply consider the existing grid infrastructure and services, where peers (individual/community) should lend a hand for grid operation to enhance resilience and flexibility. In this respect, C-MG structures with centralised control (operated and managed by microgrid operator/LEMO) can be the best choice for future local energy communities (C-MG4, 5-as shown in Table 6). Depending on the control mechanism, 
multiple cluster-based microgrids and LEM (C-MG7) can also be beneficial for the utility, consumer and community.

- Social aspect: One of the core values of introducing community-based microgrid solutions/structures is to increase the social engagement of the energy citizens in the community. Through this involvement, community citizens would believe that environment-friendly clean energy solutions and the operation of microgrids through active management systems can enhance the quality of their life and the lives of their neighbours. Though a good number of projects are already being demonstrated globally, the social values of the successful operation and management of C-MG solutions are not sufficiently addressed yet. Easy operation, utility-supportive and market participation aspects could further encourage the energy citizens to increase the social bonding by developing C-MG solutions (C-MG4, seven types of solutions could be the best options). The Living Lab approach could be one of the best ways to understand the social benefits of implementing C-MG solutions in real energy communities.

Table 6. Summary of findings for different C-MG architecture.

\begin{tabular}{|c|c|c|c|c|c|c|}
\hline \multirow{2}{*}{$\begin{array}{l}\text { C-MG } \\
\text { Structure }\end{array}$} & \multicolumn{3}{|c|}{ Control Prospective } & \multirow{2}{*}{$\begin{array}{c}\text { Grid } \\
\text { Flexibility }\end{array}$} & \multirow{2}{*}{$\begin{array}{c}\text { Market Perspective } \\
\text { LEM/Wholesale * }\end{array}$} & \multirow{2}{*}{$\begin{array}{c}\text { Social } \\
\text { Engagement }\end{array}$} \\
\hline & Centralised & Distributed & Decentralised & & & \\
\hline C-MG1 & $X$ & $\sqrt{ }$ & $\sqrt{ }$ & Low & LEM & Low \\
\hline C-MG2 & $\sqrt{ }$ & $\sqrt{ }$ & & Moderate & LEM/Wholesale * & Moderate \\
\hline C-MG3 & $\sqrt{ }$ & $x$ & $X$ & Low & LEM/Wholesale * & Moderate \\
\hline C-MG4 & $\sqrt{ }$ & $x$ & $x$ & High & LEM/Wholesale * & High \\
\hline C-MG5 & $\sqrt{ }$ & $x$ & $x$ & High & LEM/Wholesale * & Moderate \\
\hline C-MG6 & $x$ & $\sqrt{ }$ & $\sqrt{ }$ & Low & LEM/Wholesale * & Moderate \\
\hline C-MG7 & $\sqrt{ }$ & $\sqrt{ }$ & $\sqrt{ }$ & Low-High & LEM/Wholesale * & High \\
\hline
\end{tabular}

\section{Conclusions}

Consumers' active participation in decarbonising the local electricity network could be one of the key pathways to achieving the clean energy targets at the local, national and EU levels. Existing and emerging technological solutions are being implemented for the development of microgrids and smart grid networks, consumer engagement, LEM formation and coordination with WEM. Solutions are being tested and demonstrated in many places, and their impact is foreseen to grow in this decade. This article has reviewed the advancements in the formation of community-based microgrid (C-MG) solutions with a special focus on utility-friendly integration, consumer and community involvement, energy market development and social bonding enhancement. In the future academic study and industry deployment of the C-MG solutions, this critical evaluation of C-MG architecture based on the C-MG asset connection could be useful. In light of this, the C-MG solutions were reviewed. The authors have proposed the C-MG architectural layers to align with SGAM layers so that future research and development of C-MG solutions can easily be integrated with the smart grid network. C-MG structures along with their pros and cons and ways of engaging in the energy market and society have also been discussed to answer the research questions. Findings and recommendations have been outlined that will effectively increase the research and implementation of C-MG solutions towards the decarbonisation of local electricity networks and could now be readily selected and designed following the resource availability.

Author Contributions: Conceptualization, S.K., Y.S., G.D., A.P.; methodology, R.T., S.P., S.K., Y.S., F.Z.; investigation, R.T., S.P., S.K.; resources, R.T., S.P., S.K., A.P.; writing—original draft preparation, R.T., S.P., S.K., B.B., G.D., F.Z.; writing-review and editing, S.K., S.P., B.B., Y.S., F.Z., G.D., A.P.; supervision, S.K., A.P.; project administration, S.K.; funding acquisition, S.K. All authors have read and agreed to the published version of the manuscript. 
Funding: This research was funded by [Department of the Environment, Climate and Communications ] grant number [R19183] and The APC was funded by [MDPI].

Acknowledgments: This work is part of the MiFIC project and the IEA task GO-P2P. The authors in IERC thankfully acknowledge the support from the Department of the Environment, Climate and Communications and the Sustainable Energy Authority of Ireland. Acknowledgement is also given to "The Noun Project" [89] for icons used in this paper.

Conflicts of Interest: The authors declare no conflict of interest.

\section{References}

1. Integrated Local Energy Systems (Energy Islands): International Cooperation with India I Euraxess. Available online: https: / / euraxess.ec.europa.eu/worldwide/india/integrated-local-energy-systems-energy-islands-international-cooperation-india (accessed on 17 January 2022).

2. ERA-Net Smart Energy Systems: Innovation for Smart Energy Systems in Europe. Available online: https://www.eranetsmartenergysystems.eu/ (accessed on 17 January 2022).

3. European Parliament. Directive 2019/944 on Common Rules for the Internal Market for Electricity. Off. J. Eur. Union 2019, 50, 30.

4. Caramizaru, A.; Uihlein, A. Energy Communities: An Overview of Energy and Social Innovation, EUR 30083 EN; Publications Office of the European Union: Luxembourg, 2020. [CrossRef]

5. Tenti, P.; Caldognetto, T. A General Approach to Select Location and Ratings of Energy Storage Systems in Local Area Energy Networks. IEEE Trans. Ind. Appl. 2019, 55, 6203-6210. [CrossRef]

6. Paudel, A.; Chaudhari, K.; Long, C.; Gooi, H.B. Peer-to-Peer Energy Trading in a Prosumer-Based Community Microgrid: A Game-Theoretic Model. IEEE Trans. Ind. Electron. 2019, 66, 6087-6097. [CrossRef]

7. Tedesco, F.; Mariam, L.; Basu, M.; Casavola, A.; Conlon, M.F. Economic Model Predictive Control-Based Strategies for CostEffective Supervision of Community Microgrids Considering Battery Lifetime. IEEE J. Emerg. Sel. Top. Power Electron. 2015, 3, 1067-1077. [CrossRef]

8. Rosado, S.P.; Khadem, S.K. Development of Community Grid: Review of Technical Issues and Challenges. IEEE Trans. Ind. Appl. 2019, 55, 1171-1179. [CrossRef]

9. Taft, J.D. Grid Architecture: A Core Discipline for Grid Modernization. IEEE Power Energy Mag. 2019, 17, 18-28. [CrossRef]

10. Forum, E. Pan-European Forum for R \& I on Smart Grids, Flexibility and Local Energy Networks. 2020-2021. Available online: https:/ / pantera-platform.eu/wp-content/uploads/2021/02/PANTERA-D2.3.pdf. (accessed on 17 November 2021).

11. Haney, A.B.; Pollitt, M.G. New models of public ownership in energy. Int. Rev. Appl. Econ. 2013, 27, 174-192. [CrossRef]

12. Council of European Energy Regulators (CEER) CEER 2022-2025 Strategy Empowering Consumers for the Energy Transition. 2021. Available online: https:/ / www.ceer.eu/documents/104400/-/-/4a783339-46cb-1e8c-c3de-c0fe7ea52076 (accessed on 17 November 2021).

13. Transition, L.E.; Neutrality, C. CEER-BEUC 2030 VISION Long-term Energy Transition for Sustainability and Climate Neutrality: Long-term Energy Transition for Sustainability and Climate Neutrality. Available online: https:/ / ec.europa.eu/clima/eu-action/ climate-strategies-targets/2050-long-term-strategy_en. (accessed on 17 November 2021).

14. Syed, M.M.; Morrison, G.M. A Rapid Review on Community Connected Microgrids. Sustainability 2021, 13, 6753. [CrossRef]

15. Cox, D.J. Microgrid Infrastructure Modeling for Residential Microgrids. In Proceedings of the 2007 IEEE Power Engineering Society General Meeting, Tampa, FL, USA, 24-28 June 2007; pp. 1-6. [CrossRef]

16. Wu, L.; Ortmeyer, T.; Li, J. The community microgrid distribution system of the future. Electr. J. 2016, 29, 16-21. [CrossRef]

17. Bourgeois, T.; Gerow, J.; Litz, F.; Martin, N. Community Microgrids: Smarter, Cleaner. Pace Energy Clim. Cent. 2013, 1-23. Available online: http://nyssmartgrid.com/wp-content/uploads/Pace-Energy-and-Climate-Center-Community-Microgrids. pdf. (accessed on 21 December 2021).

18. Council of European Energy Regulators. Regulatory Aspects of Self-Consumption and Energy Communities; CEER Report C18CRM9_DS7-05-03; Council of European Energy Regulators asbl: Brussels, Belgium, 2019; p. 53.

19. Gui, E.M.; Diesendorf, M.; MacGill, I. Distributed energy infrastructure paradigm: Community microgrids in a new institutional economics context. Renew. Sustain. Energy Rev. 2017, 72, 1355-1365. [CrossRef]

20. Zhang, C.; Wu, J.; Zhou, Y.; Cheng, M.; Long, C. Peer-to-Peer energy trading in a Microgrid. Appl. Energy 2018, 220, 1-12. [CrossRef]

21. Paladin, A.; Das, R.; Wang, Y.; Ali, Z.; Kotter, R.; Putrus, G.; Turri, R. Micro market based optimisation framework for decentralised management of distributed flexibility assets. Renew. Energy 2021, 163, 1595-1611. [CrossRef]

22. Bruinenberg, J.; Colton, L.; Darmois, E.; Dorn, J.; Doyle, J.; Elloumi, O.; Englert, H.; Forbes, R.; Heiles, J.; Hermans, P.; et al. CEN-CENELEC-ETSI: Smart Grid Coordination Group-Smart Grid Reference Architecture Report 2.0. 2012. Available online: https:/ / ec.europa.eu/energy/sites/ener/files/documents/xpert_group1_reference_architecture.pdf (accessed on 30 December 2021).

23. Mazzola, L.; Denzler, A.; Christen, R. Peer-to-Peer Energy Trading in Microgrids: Towards an Integrated Open and Distributed Market. In Proceedings of the 2020 International Conference on Electrical Engineering and Control Technologies (CEECT), Melbourne, VIC, Australia, 10-13 December 2020; pp. 1-10. [CrossRef] 
24. Martin-Martínez, F.; Sánchez-Miralles, A.; Rivier, M. A literature review of Microgrids: A functional layer based classification. Renew. Sustain. Energy Rev. 2016, 62, 1133-1153. [CrossRef]

25. Vaahedi, E.; Nodehi, K.; Heim, D.; Rahimi, F.; Ipakchi, A. The Emerging Transactive Microgrid Controller: Illustrating Its Concept, Functionality, and Business Case. IEEE Power Energy Mag. 2017, 15, 80-87. [CrossRef]

26. Carpintero-Rentería, M.; Santos-Martín, D.; Guerrero, J.M. Microgrids literature review through a layers structure. Energies 2019, 12, 4381. [CrossRef]

27. Siano, P.; De Marco, G.; Rolán, A.; Loia, V. A Survey and Evaluation of the Potentials of Distributed Ledger Technology for Peer-to-Peer Transactive Energy Exchanges in Local Energy Markets. IEEE Syst. J. 2019, 13, 3454-3466. [CrossRef]

28. Trivedi, R.; Khadem, S. Peak Demand Management and Schedule Optimisation for Energy Storage through the Machine Learning Approaches. In Proceedings of the IEEE EUROCON 2021-19th International Conference on Smart Technologies, Lviv, Ukraine, 6-8 July 2021; pp. 157-163. [CrossRef]

29. Hatziargyriou, N. Microgrids: Architectures and Control, 1st ed.; Wiley-IEEE Press: Chichester, UK, 2014; ISBN 978-1-118-72068-4.

30. Tao, L.; Schwaegerl, C.; Narayanan, S.; Zhang, J.H. From laboratory Microgrid to real markets—Challenges and opportunities. In Proceedings of the 8th International Conference on Power Electronics-ECCE, Jeju, Korea, 30 May-3 June 2011 ; pp. $264-271$. [CrossRef]

31. More Microgrids Report on the Technical, Social, Economic, and Environmental Benefits Provided by Microgrids on Power System Operation. WPG. Evaluation of the System Performance on Power System Operation. 2009. Available online: http://www. microgrids.eu/documents/668.pdf (accessed on 30 December 2021).

32. Shamsi, P.; Xie, H.; Longe, A.; Joo, J.Y. Economic Dispatch for an Agent-Based Community Microgrid. IEEE Trans. Smart Grid 2016, 7, 2317-2324. [CrossRef]

33. Hyytinen, K.; Toivonen, M. Future energy services: Empowering local communities and citizens. Foresight 2015, 17, 349-364. [CrossRef]

34. Bentley, E.; Kotter, R.; Wang, Y.; Das, R.; Putrus, G.; Van Der Hoogt, J.; Van Bergen, E.; Warmerdam, J.; Heller, R.; Jablonska, B. Pathways to energy autonomy-Challenges and opportunities. Int. J. Environ. Stud. 2019, 76, 893-921. [CrossRef]

35. Gill, S.; Plecas, M.; Kockar, I. Coupling Demand and Distributed Generation to Accelerate Renewable Connections: Options for the Accelerating Renewable Connections Project; University of Strathclyde: Glasgow, UK, 2014.

36. Roberts, M.B.; Bruce, A.; MacGill, I. Opportunities and barriers for photovoltaics on multi-unit residential buildings: Reviewing the Australian experience. Renew. Sustain. Energy Rev. 2019, 104, 95-110. [CrossRef]

37. Parra, D.; Swierczynski, M.; Stroe, D.I.; Norman, S.A.; Abdon, A.; Worlitschek, J.; O’Doherty, T.; Rodrigues, L.; Gillott, M.; Zhang, X.; et al. An interdisciplinary review of energy storage for communities: Challenges and perspectives. Renew. Sustain. Energy Rev. 2017, 79, 730-749. [CrossRef]

38. Mariam, L. Modelling of an Intelligent Microgrid System in a Smart Grid Network; Technological University Dublin: Dublin, Ireland, 2018. [CrossRef]

39. Gui, E.M.; MacGill, I. Typology of future clean energy communities: An exploratory structure, opportunities, and challenges. Energy Res. Soc. Sci. 2018, 35, 94-107. [CrossRef]

40. Zou, H.; Mao, S.; Wang, Y.; Zhang, F.; Chen, X.; Cheng, L. A Survey of Energy Management in Interconnected Multi-Microgrids. IEEE Access 2019, 7, 72158-72169. [CrossRef]

41. Carrión, G.A.; Cintrón, R.A.; Rodríguez, M.A.; Sanabria, W.E.; Reyes, R.; O’Neill-Carrillo, E. Community Microgrids to Increase Local Resiliency. In Proceedings of the 2018 IEEE International Symposium on Technology and Society (ISTAS), Washington, DC, USA, 13-14 November 2018; pp. 1-7. [CrossRef]

42. Burmester, D.; Rayudu, R.; Seah, W.; Akinyele, D. A review of nanogrid topologies and technologies. Renew. Sustain. Energy Rev. 2017, 67, 760-775. [CrossRef]

43. Ajaei, F.B.; Mohammadi, J.; Stevens, G.; Akhavan, E. Hybrid AC/DC microgrid configurations for a net-zero energy community. In Proceedings of the 2019 IEEE/IAS 55th Industrial and Commercial Power Systems Technical Conference (I\&CPS), Calgary, AB, Canada, 5-8 May 2019. [CrossRef]

44. Warneryd, M.; Håkansson, M.; Karltorp, K. Unpacking the complexity of community microgrids: A review of institutions' roles for development of microgrids. Renew. Sustain. Energy Rev. 2020, 121, 109690. [CrossRef]

45. Suk, H.; Yadav, A.; Hall, J. Scalability considerations in the design of microgrids to support socioeconomic development in rural communities. ASME Int. Mech. Eng. Congr. Expo. Proc. 2018, 13, 1-9. [CrossRef]

46. Soshinskaya, M.; Crijns-Graus, W.H.J.; Guerrero, J.M.; Vasquez, J.C. Microgrids: Experiences, barriers and success factors. Renew. Sustain. Energy Rev. 2014, 40, 659-672. [CrossRef]

47. Alvial-Palavicino, C.; Garrido-Echeverría, N.; Jiménez-Estévez, G.; Reyes, L.; Palma-Behnke, R. A methodology for community engagement in the introduction of renewable based smart microgrid. Energy Sustain. Dev. 2011, 15, 314-323. [CrossRef]

48. Gollwitzer, L. Community-Based Micro Grids: A Common Property Resource Problem; STEPS Centre: Brighton, UK, 2014.

49. Gopstein, A.; Nguyen, C.; Byrnett, D.S.; Worthington, K.; Villarreal, C. Framework and Roadmap for Smart Grid Interoperability Standards regional Roundtables Summary Report; National Institute of Standards and Technology (NIST): Gaithersburg, MD, USA, 2020.

50. FERRAZ, F.S. IDeM: An Identity-Driven Middleware for Interoperable and Heterogeneous Systems; Universidade Federal de Pernambuco: Recife, Brazil, 2016. 
51. Basso, T. IEEE 1547 and 2030 Standards for Distributed Energy Resources Interconnection and Interoperability with the Electricity Grid; National Renewable Energy Lab. (NREL): Golden, CO, USA, 2014. [CrossRef]

52. European Commission M441. 2009. Available online: https://ec.europa.eu/growth/tools-databases/mandates/index.cfm? fuseaction=search.detail\&id=421\# (accessed on 17 November 2021).

53. European Commission. Standardization Mandate to CEN, CENELEC and ETSI Concerning the Charging of Electric Vehicles, M/468 EN. European Commission; European Commission: Brussels, Belgium, 2010. Available online: https://ec.europa.eu/growth/toolsdatabases/mandates/index.cfm?fuseaction=search.detail\&id=450 (accessed on 17 November 2021).

54. European Commission. M/490 Smart Grid Mandate Standardization Mandate to European Standardisation Organisations (ESOs) to Support European Smart Grid Deployment; European Commission: Brussels, Belgium, 2011. Available online: https://ec.europa.eu/ growth/tools-databases/mandates/index.cfm?fuseaction=search.detail\&id=475\# (accessed on 17 November 2021).

55. European Commission. M/530 COMMISSION IMPLEMENTING DECISION C(2015) 102 Final of 20.1.2015; European Commission: Brussels, Belgium, 2015. Available online: https:/ / ec.europa.eu/growth/tools-databases/mandates/index.cfm?fuseaction= search.detail\&id=548\# (accessed on 17 November 2021).

56. IEEE 1547-2018-IEEE Standard for Interconnection and Interoperability of Distributed Energy Resources with Associated Electric Power Systems Interfaces. Available online: https:/ /standards.ieee.org/standard/1547-2018.html (accessed on 14 December 2021).

57. IEEE Standards Committee; IEEE Standards Coordinating Committee 21 on Fuel Cells, P.; Institute of Electrical and Electronics Engineers; IEEE-SA Standards Board. IEEE Guide for Smart Grid Interoperability of Energy Technology and Information Technology Operation with the Electric Power System (EPS), End-Use Applications and Loads; IEEE: Piscataway, NJ, USA, 2011 ; Volume 110. [CrossRef]

58. P2040 — Standard for General Requirements for Fully Automated Vehicles Driving on Public Roads. Available online: https: / / standards.ieee.org/project/2040_3.html. (accessed on 25 November 2021).

59. IEEE SA-IEEE 802. Available online: https:// standards.ieee.org/featured/802/index.html (accessed on 25 November 2021).

60. IEC 61850:2021 SER I IEC Webstore I LVDC. Available online: https: / / webstore.iec.ch/publication/ 6028 (accessed on 25 November 2021).

61. IEC 62325-301:2018 I IEC Webstore. Available online: https://webstore.iec.ch/publication/31487 (accessed on 25 November 2021).

62. IEC-Smart Grid Standards Map. Available online: http:/ / smartgridstandardsmap.com/ (accessed on 28 November 2021).

63. Bower, W.I.; Ton, D.T.; Guttromson, R.; Glover, S.F.; Stamp, J.E.; Bhatnagar, D.; Reilly, J. The Advanced Microgrid. Integration and Interoperability; Sandia National Lab.: Albuquerque, NM, USA; Livermore, CA, USA, 2014. [CrossRef]

64. O'Fallon, C.; Gopstein, A. Economics of Interoperability in the Context of Smart Grid Architectures. NIST Spec. Publ. 1900, 604, 1900-604.

65. Dudjak, V.; Neves, D.; Alskaif, T.; Khadem, S.; Pena-Bello, A.; Saggese, P.; Bowler, B.; Andoni, M.; Bertolini, M.; Zhou, Y.; et al. Impact of local energy markets integration in power systems layer: A comprehensive review. Appl. Energy 2021, $301,117434$. [CrossRef]

66. Bjarghov, S.; Löschenbrand, M.; Saif, A.U.N.I.; Pedrero, R.A.; Pfeiffer, C.; Khadem, S.K.; Rabelhofer, M.; Revheim, F.; Farahmand, H. Developments and Challenges in Local Electricity Markets: A Comprehensive Review. IEEE Access 2021, 9, 58910-58943. [CrossRef]

67. Saif, A.U.N.I.; Khadem, S.K. Consumer-centric Electricity Market: Review of key European projects. In Proceedings of the 2020 17th International Conference on the European Energy Market (EEM), Stockholm, Sweden, 16-18 September 2020; pp. 1-6. [CrossRef]

68. Ellabban, O.; Abu-Rub, H. Smart grid customers' acceptance and engagement: An overview. Renew. Sustain. Energy Rev. 2016, 65, 1285-1298. [CrossRef]

69. Eadson, W.; Bull, R. Citizen Engagement in local Energy Decision-Making: Literature and Policy Background; Sheffield Hallam University: Sheffield, UK, 2020. [CrossRef]

70. Gupta, R.; Zahiri, S. Enhancing User Engagement in Local Energy Initiatives using Smart Local Energy Engagement Tools (SLEETs). In Proceedings of the 6th European Conference on Behaviour and Energy Efficiency, Copenhagen, Denmark, 21-23 April 2021.

71. Meeuw, A.; Schopfer, S.; Ryder, B.; Wortmann, F. LokalPower: Enabling local energy markets with user-driven engagement. In Proceedings of the Extended Abstracts of the 2018 CHI Conference on Human Factors in Computing Systems, Montreal, QC, Canada, 20 April 2018. [CrossRef]

72. Becker, S.; Kunze, C. Transcending community energy: Collective and politically motivated projects in renewable energy (CPE) across Europe. People Place Policy 2014, 8, 180-191. [CrossRef]

73. Hanna, R.; Ghonima, M.; Kleissl, J.; Tynan, G.; Victor, D.G. Evaluating business models for microgrids: Interactions of technology and policy. Energy Policy 2017, 103, 47-61. [CrossRef]

74. Abada, I.; Ehrenmann, A.; Lambin, X. On the Viability of Energy Communities. Energy J. 2020, 41, 113-150. [CrossRef]

75. Ramos, A.; De Jonghe, C.; Gómez, V.; Belmans, R. Realizing the smart grid's potential: Defining local markets for flexibility. Util. Policy 2016, 40, 26-35. [CrossRef] 
76. Mengelkamp, E.; Staudt, P.; Garttner, J.; Weinhardt, C. Trading on local energy markets: A comparison of market designs and bidding strategies. Int. Conf. Eur. Energy Mark. EEM 2017. [CrossRef]

77. Lezama, F.; Soares, J.; Hernandez-Leal, P.; Kaisers, M.; Pinto, T.; Vale, Z. Local Energy Markets: Paving the Path Toward Fully Transactive Energy Systems. IEEE Trans. Power Syst. 2019, 34, 4081-4088. [CrossRef]

78. Kirpes, B.; Mengelkamp, E.; Schaal, G.; Weinhardt, C. Design of a microgrid local energy market on a blockchain-based information system. It-Inf. Technol. 2019, 61, 87-99. [CrossRef]

79. Brolin, M.; Pihl, H. Design of a local energy market with multiple energy carriers. Int. J. Electr. Power Energy Syst. 2020, 118, 105739. [CrossRef]

80. Ableitner, L.; Meeuw, A.; Schopfer, S.; Tiefenbeck, V.; Wortmann, F.; Wörner, A. Quartierstrom-Implementation of a Real World Prosumer Centric Local Energy Market in Walenstadt, Switzerland; Cornell Univ: Ithaca, NY, USA, 2019.

81. Global Observatory on Peer-to-Peer Energy Trading-UsersTCP. Available online: https://userstcp.org/task/peer-to-peerenergy-trading/1121 (accessed on 21 December 2021).

82. Schwaegerl, C.; Tao, L. Quantification of Technical, Economic, Environmental and Social Benefits of Microgrid Operation. Microgrids 2013, 275-313. [CrossRef]

83. Palma-Behnke, R.; Ortiz, D.; Reyes, L.; Jiménez-Estévez, G.; Garrido, N. A social SCADA approach for a renewable based microgrid-The Huatacondo project. IEEE Power Energy Soc. Gen. Meet. 2011. [CrossRef]

84. Mastelic, J. Stakeholders' Engagement in the Co-Design of Energy Conservation Interventions; Universite de Lausanne: Lausanne, Switzerland, 2019.

85. Martínez-Cid, R.; O'Neill-Carrillo, E. Sustainable microgrids for isolated systems. In Proceedings of the IEEE PES T\&D 2010, New Orleans, LA, USA, 19-22 April 2010. [CrossRef]

86. Santos, A.Q.; Ma, Z.; Olsen, C.G.; Jørgensen, B.N. Framework for Microgrid Design Using Social, Economic, and Technical Analysis. Energies 2018, 11, 2832. [CrossRef]

87. Ubilla, K.; Jiménez-Estévez, G.A.; Hernádez, R.; Reyes-Chamorro, L.; Irigoyen, C.H.; Severino, B.; Palma-Behnke, R. Smart microgrids as a solution for rural electrification: Ensuring long-term sustainability through cadastre and business models. IEEE Trans. Sustain. Energy 2014, 5, 1310-1318. [CrossRef]

88. Bridging the Gap between Open and User Innovation? In Exploring the Value of Living Labs as a Means to Structure User Contribution and Manage Distributed Innovation; Vrije Universiteit Brussel: Brussels, Belgium; Ghent University: Ghent, Belgium, 2015.

89. Noun Project: Free Icons \& Stock Photos for Everything. Available online: https://thenounproject.com/ (accessed on 10 November 2021). 